\title{
PROPORCIONES, ALEGORÍAS, ÁNGELES MÚSICOS Y EJECUCIÓN HISTÓRICAMENTE INFORMADA EN LOS ÓRGANOS GEMELOS DE LA CATEDRAL METROPOLITANA DE MÉXICO
}

\author{
PROPORTIONS, ALLEGORIES, ANGELS MUSICIANS AND HIP, \\ IN THE TWIN ORGANS AT THE CATEDRAL METROPOLITANA OF MEXICO
}

José Antonio Guzmán Bravo

Universidad Nacional Autónoma de México

\section{Resumen}

Análisis estético de las cajas gemelas de los órganos de la Catedral de México. Correspondencia entre las proporciones arquitectónicas del barroco y las proporciones aritmético-musicales pitagóricas. La composición fónica de un retablo sonoro. Los cuerpos de flautados de fachada, los ecos internos, los flautados de nave y la trompetería horizontal. La expresión sonora de las calles, platabandas, cornisas y ventanas de las cajas de cedro y ayacahuite de los órganos de Catedral. Los dorados y rubicundos ángeles en instrumentos mudos. Iconografía organológica. Instrumentos prehispánicos, clásicos grecolatinos, góticos, renacentistas y barrocos; un despliegue enciclopédico. Disposición actual de los registros. Diseños de ambas fachadas.

La composición original de los tubos. Resultado lumínico y cromático. Restauración del brillo original y de los figurones pintados en las bocas de las flautas de fachada.

Documentos en que debe apoyarse toda restauración; mantenimiento y cuidado para que estando en uso no se deteriore. Preservación y promoción del archivo musical de catedral. Función social y sentido cultural al restaurar un instrumento patrimonial único.

Uso litúrgico y académico para preservar y promover la cultura organística.

El instrumento como fuente de investigación; la Ejecución Históricamente Informada (EHI).

\section{Palabras clave}

Órganos gemelos, Catedral Metropolitana de México, Nassarre, organería novohispana, EHI.

\begin{abstract}
:
An aesthetic analysis of the twin organs of Cathedral of Mexico. Correspondence between Pythagorean and Baroque arithmetical, musical and architectural proportions. The phonic composition of the acoustic altarpiece. The bodies of façade flutes, the internal echoes, ship flutes and horizontal trumpet. The sonorous expression of the streets, platforms, cornices and windows of the boxes of cedar and ayacahuite of the organs. The golden and ruddy angels on mute instruments. Organological iconography. Prehispanic instruments, classical Greco-Roman, Gothic, Renaissance and Baroque; an encyclopedic display. Current disposition of records. Designs of both facades.

The original composition of the tubes. Light and color result. Restoration of the original brightness and the painted figures in the mouths of the flute façade.

Documents in which all restoration must be supported; maintenance and care. Preservation and promotion of the Cathedral's musical archive. Social function and cultural when restoring a patrimonial instrument. culture.

Liturgical and academic use to preserve and promote organ

The instrument as a source of research; The Historically Informed Performance (HIP)
\end{abstract}

Key words:

Twin organs, Catedral Metropolitana of Mexico, Nassarre, organ building of New Spain, HIP. 


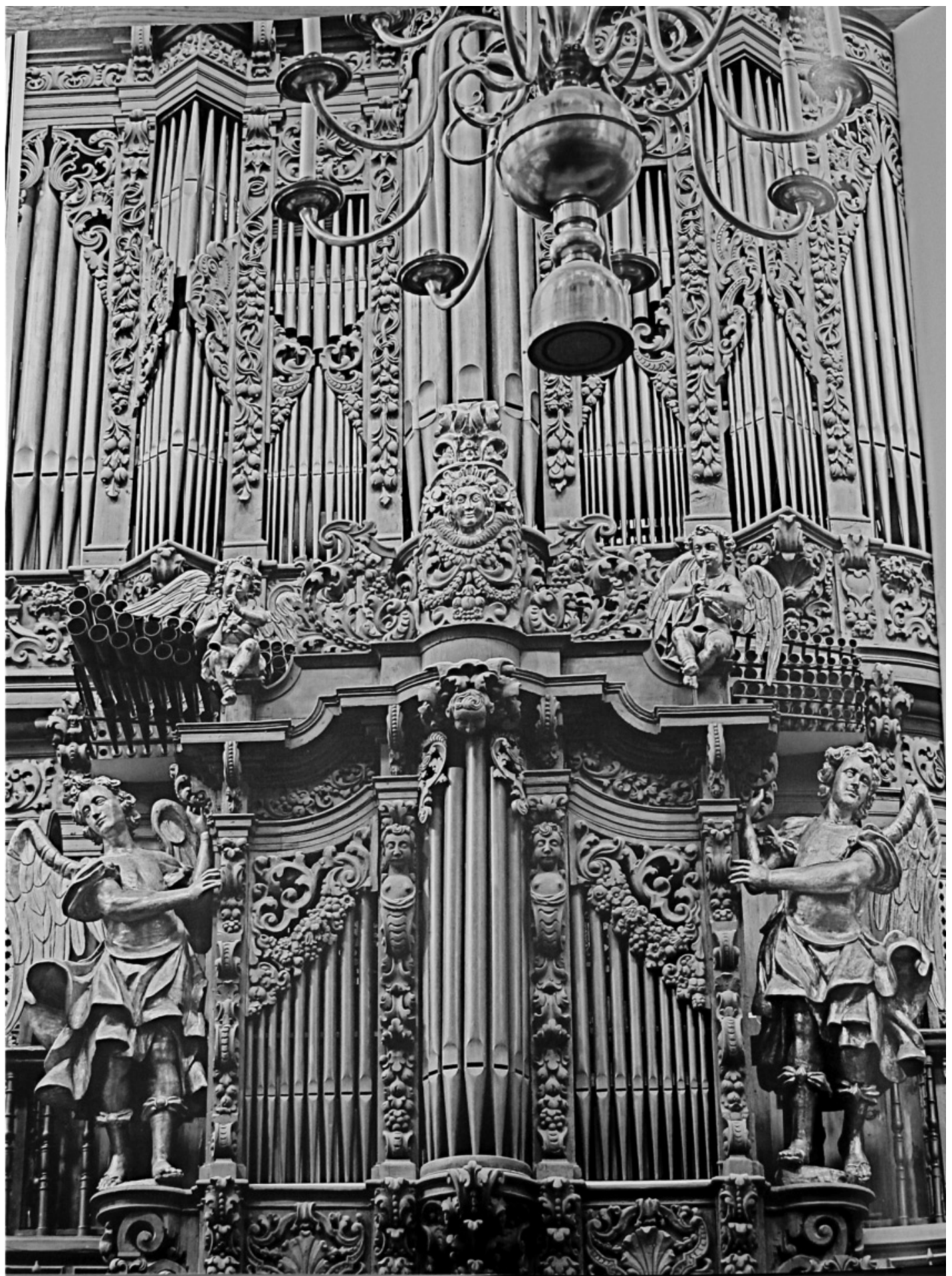

Imagen I: Cadereta exterior, órgano del Evangelio. 


\section{PROPORCIONES, ALEGORÍAS, ÁNGELES MÚSICOS Y EJECUCIÓN HISTÓRICAMENTE INFORMADA EN LOS ÓRGANOS GEMELOS DE LA CATEDRAL DE MÉXICO}

Desde sus altas tribunas corales, al centro de la nave mayor de la catedral, los órganos gemelos construidos por Joseph Nassarre entre 1734 y 1736 han presidido las grandes ocasiones de nuestra historia, no siempre felices, con una presencia que ha sido capaz de colmar el ámbito sonoro con sus ricos timbres de flautados, lengüetería, nasardos y mixturas con agudos brillos de címbalas.

La maestría y organización de Nassarre y de sus ayudantes les permitió entregar los instrumentos en el plazo de 30 meses y el costo de 48,000 pesos de oro convenidos, lo que ameritó una gratificación de dos mil pesos en oro de minas y reconocimiento por parte del Cabildo. Los órganos resultaron en todo semejantes ${ }^{1}$, un par de órganos gemelos a partir del diseño integral de Nassarre, ejecutado con auxilio de su taller de notables carpinteros, ebanistas, talladores y doradores.

Tras décadas de abandono, abusos y desastres, los órganos catedralicios hoy se recuperan y podemos gozar de nuevo estos ricos timbres y sonoridades a través de la restauración integral de ambos encomendada al taller del Maestro Gerhard Grenzing en El Papiol, Barcelona.

\section{LA UBICACIÓN DE LAS CAJAS DE LOS ÓRGANOS}

México hereda una antigua práctica castellana de colocar el coro al centro de la nave mayor inmediata al altar mayor como sucede en muchas catedrales, colegiatas e iglesias principales de España.

Lo que favoreció el desarrollo de una forma de simetría visual y sonora que se hacía efectiva mediante la colocación de coros y órganos enfrentados, tal como ocurre en las catedrales de Cuenca y Málaga, por ejemplo².

La tradición arquitectónica que vincula espacialmente el Coro con el Altar Mayor, en correspondencia con la salida y puesta del sol, proviene de las antiguas basílicas helenobizantinas, que generaban a lo largo del día ritual, prácticas litúrgicas antifonales y policorales correspondientes a las horas canónicas marcadas por el curso del sol. Hay que recordar que la Catedral de México está orientada de norte a sur por lo que el curso del sol corre sobre el transepto de

1 Ya veremos que existen pequeñas diferencias entre ambos órganos. Las fachadas son idénticas, no así algunos mecanismos internos, registros y detalles. La diferencia en el número de registros entre ambos se debe a la última restauración de las contras y bombardas y al medio teclado solista agregado al órgano del Evangelio en 1808.

2 GALÁN (2009): 58. oriente a poniente, iluminando los ventanales colocados a lo largo de las naves en la mañana y en la tarde.

El sistema de clases y castas del absolutismo aquí como en Europa, separa y delimita -con ricos barandales metálicos, pajes de bronce blandiendo cirios, infinitas balaustradas y altas rejas de tumbago y metales dorados- dónde deben sentarse y colocarse según su rango, los dignatarios del cabildo, nobleza y autoridades y dónde cofrades, clero menor o frailes con el pueblo de fieles ordinarios.

El coro, voz y pulso de la Catedral de México, estuvo destinado desde su diseño original a ocupar un lugar privilegiado en la planta por razones puramente acústicas, litúrgicas, artísticas e históricas, que comparte con otras catedrales del mundo hispánico.

El musicólogo Andrés Cea Galán hace un recuento de los principales órganos gemelos en España y Portugal, instalados principalmente en coros ubicados en la nave central ${ }^{3}$. También menciona los Nassarre construidos para Guadalajara, Jalisco (un órgano grande y uno mediano) ya desaparecidos y los órganos gemelos de la Catedral de México (Nassarre 173436, cajas idénticas y algunas mínimas diferencias de registros).

Las cajas de los órganos son verdaderos retablos en los que las flautas y trompetas toman el sitio de las imágenes pintadas y de las esculturas, asomando sus cilindros de estaño y plomo por las ventanas que consiente la estructura tallada de las platabandas y de los castillos circulares o en punta de diamante. Ciñen cada uno de los cuatro pisos de las cajas monumentales, fornidas cornisas que sostienen esculturas de ángeles músicos a punto de vuelo, una orquesta en suspenso.

Estas obras, realizadas por maestros escultores y ensambladores pertenecientes a gremios urbanos de españoles y criollos son el resultado de la calidad artesanal lograda en el barroco novohispano que pretendía alejarse de los modelos renacentistas indo-misionales del siglo anterior. Los nuevos gremios acaparaban jugosos contratos y encargos principales lo que limitó la demanda de mano de obra indígena calificada para la construcción y ejecución de los órganos en las ciudades. Notables organeros indígenas que se habían formado en los talleres conventuales y que en los buenos tiempos fueron harto capaces de satisfacer las apremiantes demandas de la Evangelización ahora llevaban una dura existencia sirviendo pueblos apartados. Las condiciones desiguales impuestas a los naturales por este capitalismo primitivo, terminaron con su libre iniciativa y los convirtieron en aprendices, oficiales o criados, siempre dependientes de los patrones criollos o peninsulares y sólo siguieron gozando de cierta demanda en las comunidades rurales y en los barrios urbanos de indios.

\footnotetext{
3 GALÁN (2009): 79-83.
} 

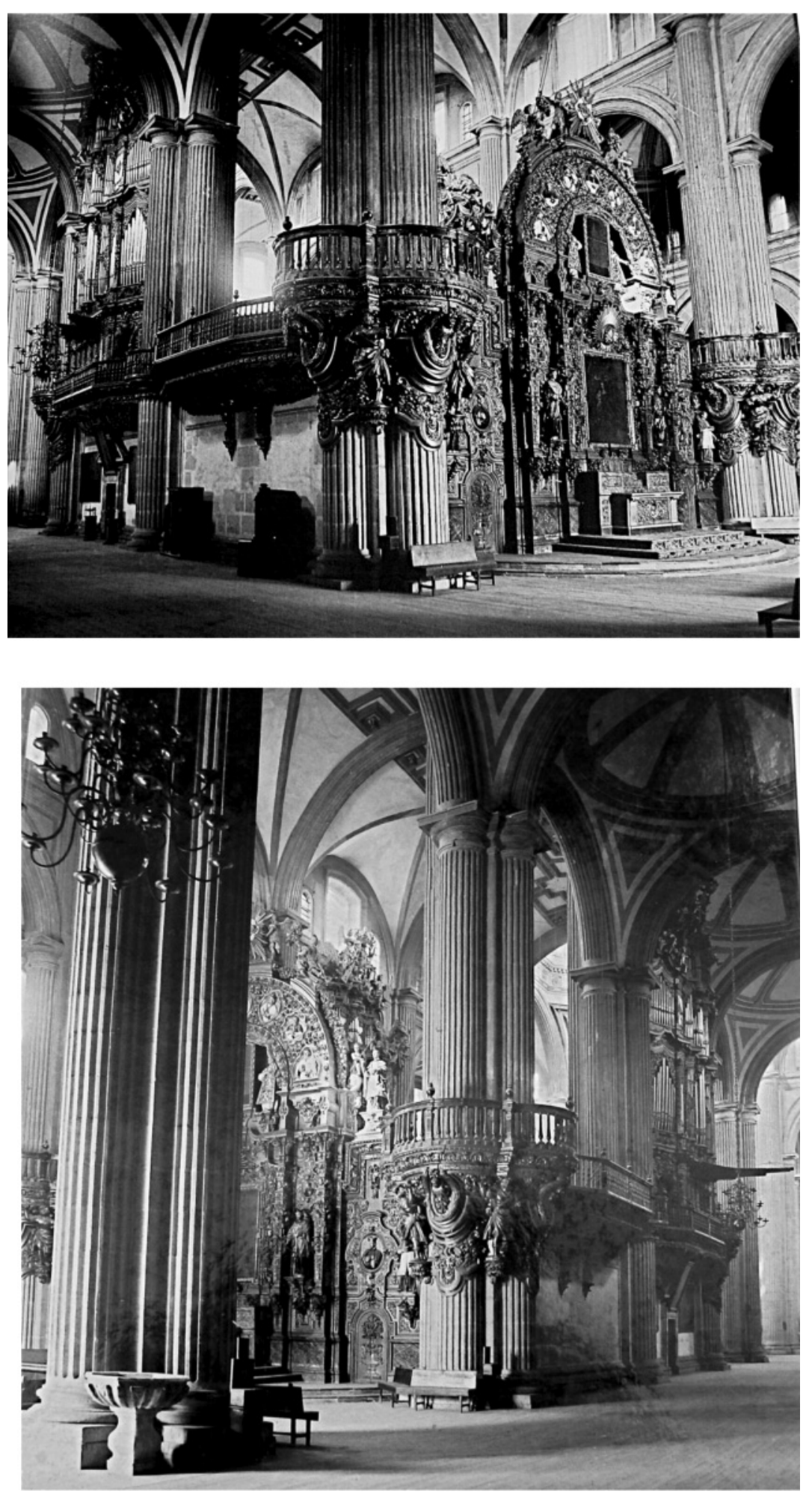

Imágenes II- III: Coro, interior Catedral, fotos Guillermo Khalo 1907. 


\section{ARQUITECTURA Y ESCULTURA SONORAS}

La notable unidad visual y sonora lograda por Nassarre en el diseño de sus órganos gemelos, de honda raigambre aragonesa y castellana, maduró en México a lo largo de los trabajos que realizó entre 1727 y 1736. Los órganos de catedral se encuentran entre los pocos sobrevivientes de esa concepción monumental y policoral del barroco en América.

En su Exacta Descripción de la Magnífica Corte Mexicana, Cabeza del Nuevo Americano Mundo (Cádiz, 1768), don Juan Manuel de San Vicente, hizo una descripción de los principales monumentos del virreinato de la Nueva España, entre los que él destaca la Catedral, cuyo coro describió con admiración:

Ocupan el ámbito de dos Arcos en dos frentes de la Nave Mayor, dos gigantes Organos de dos caras, y quatro cuerpos cada uno, cuyas hermosísimas caxas de las mas ricas, y bien talladas maderas, con los relieves dorados, tienen diez y siete varas de alto, y once de ancho, que haciendo assiento en las Tribunas del Coro, llenan todo el hueco de los Arcos, hasta sobresalir con su magnitud á los medios Puntos correspondientes; con cinco ocultos Fuelles, que impeliendo el Viento, hacen sonar dulcemente, á tres mil trescientas y cinquenta Flautas, de que se forman ochenta y seis harmoniosas mixturas, las que diariamente sirven á el Sagrado Culto, desde el dia diez de Octubre del año de mil setecientos treinta y seis, que se colocaron ${ }^{4}$.

Décadas más tarde, ya en el siglo XIX, seguirán siendo considerados como una obra sin paralelo en el ámbito hispánico; don José María del Barrio, tesorero comisionado para los trabajos de restauración del órgano del Evangelio, en su informe del 11 de diciembre de 1801 asegura que se trata de una pieza del mayor gusto, y delicadeza, y que seguramente no tiene semejantes en el Reino, ni aún en muchas de las iglesias catedrales de España 5 .

Don José María encarece el trabajo respetuoso que realizó en la restauración el organero de abolengo familiar, don Mariano Antonio Pérez de Lara

...habiendo aplicado todo su particular cuidado en guardar el debido rrespecto, a su Autor, para que sin estrabío, de sus primeras, y sabias disposiciones, tan magnífica estructura, en el día aiga esmerosamente

4 SAN VICENTE (1768): 16.

5 Fábrica Material, Archivo Cabildo Catedral Metropolitana de México (ACCMM), caja 3, exp. 5, fol. 12r. trabajado, y apurado su pericia para las distribuciones que ha abido menester. 6

En el órgano de la Epístola, la caja del órgano anterior, tallada por Juan de Rojas, era más pequeña que la actual y quizá semejante a la que años después Félix Sans de Izaguirre construyó para el órgano de la Epístola de la Catedral de Puebla. Fragmentos de celosías fueron rescatadas y parcialmente utilizados por Nassarre en la reforma de 1736, ya que en la vieja caja de tres cuerpos, no cabían las contras, la madera no estaba en buenas condiciones y no llenaba totalmente el espacio intercolumnio del gran arco, ni a lo ancho ni a lo alto, como requería el proyecto de cuatro cuerpos propuesto por Nassarre. No obstante, se salvaron y reemplearon celosías caladas sobrepuestas, cornisas, la imagen de la Virgen, la corona y otros detalles tallados, (no se sabe que hubiera ángeles en la caja de Rojas). Puede afirmarse que poco se conservó del antiguo instrumento (Sesma-Sans-Rojas), fuera de algunos registros de flautados y metal aprovechables; fue desmantelado en 1735 con el fin de usar algunos materiales que a la postre no estaban en condiciones y fueron descartados. De la cadereta interna original no quedó rastro, la externa nunca se construyó. Ni el mecanismo, ni los flautados, ni la caja actual del órgano español son los originales de 1695, Nassarre ajustó y limpió este instrumento -que funcionó mientras construía el del Evangelio- para luego reconstruirlo íntegramente en 1736. De la maquinaria original y cañería, sobrevivieron algunos registros (aunque el reporte de Flentrop, 1986), no los consigna). Algunos años después de su estreno se habló de los tubos viejos repuestos enteramente, todo el metal aprovechable fue fundido y reempleado; se mantuvieron dos de los fuelles originales -después rehechos en varias ocasiones- y la tabla de conducción de aire del secreto, así como el armazón de madera que sostenía las fachadas; todo lo que resultó aprovechable, robusto y sin polilla.

El diseño y realización en espejo de ambas caderetas externas -cuyas torretas del castillo dan al coro- y la talla de los 2 arcángeles que las sostienen, fueron otro de los aciertos formales de Nassarre, así como la disposición de la enorme caja del órgano mayor en cuatro cuerpos ascendentes con torneadas cornisas que sostienen una representación de la orquesta celestial de ángeles instrumentistas subiendo a coronar a la Virgen ${ }^{7}$. De aquí parte un simbolismo que es

6 Ibid, fol.15r.

7 Es no sólo aconsejable, sino imprescindible, planear la adecuada iluminación de sus cajas; cuatro fachadas barrocas espléndidas, dignas de recuperarse plásticamente y de ser exhibidas como un tesoro en sí mismas, al menos en las grandes festividades y durante los conciertos que los órganos protagonizan. 
fusión de alegorías eclécticas, conforme al gusto barroco novohispano.

La caja actual ya integralmente retrabajada 40 años después por Nassarre con base en la de enfrente, presenta una decoración barroca mucho más "moderna" que la muy clásica y conservadora de la sillería y que la caja original que tuvo el órgano español.

La fachada se hizo en madera de cedro, con base en motivos ornamentales de follajes que revisten finas pilastras y la particular utilización de bichas y perfiles abarrocados...8.
Estos elementos ornamentales del barroco novohispano emparentados estilísticamente con la linea churrigueresca sevillana que por entonces trabajaba Jerónimo de Balbás (con una originalidad inconfundible) y otros notables retablistas novohispanos, no obstante hicieron pensar a don Manuel Toussaint ${ }^{9}$ en un barroco afrancesado tendiente al rococó dieciochesco, es decir, más tardío que el de las nuevas cajas construidas por Nassarre entre 1734 y 1736.

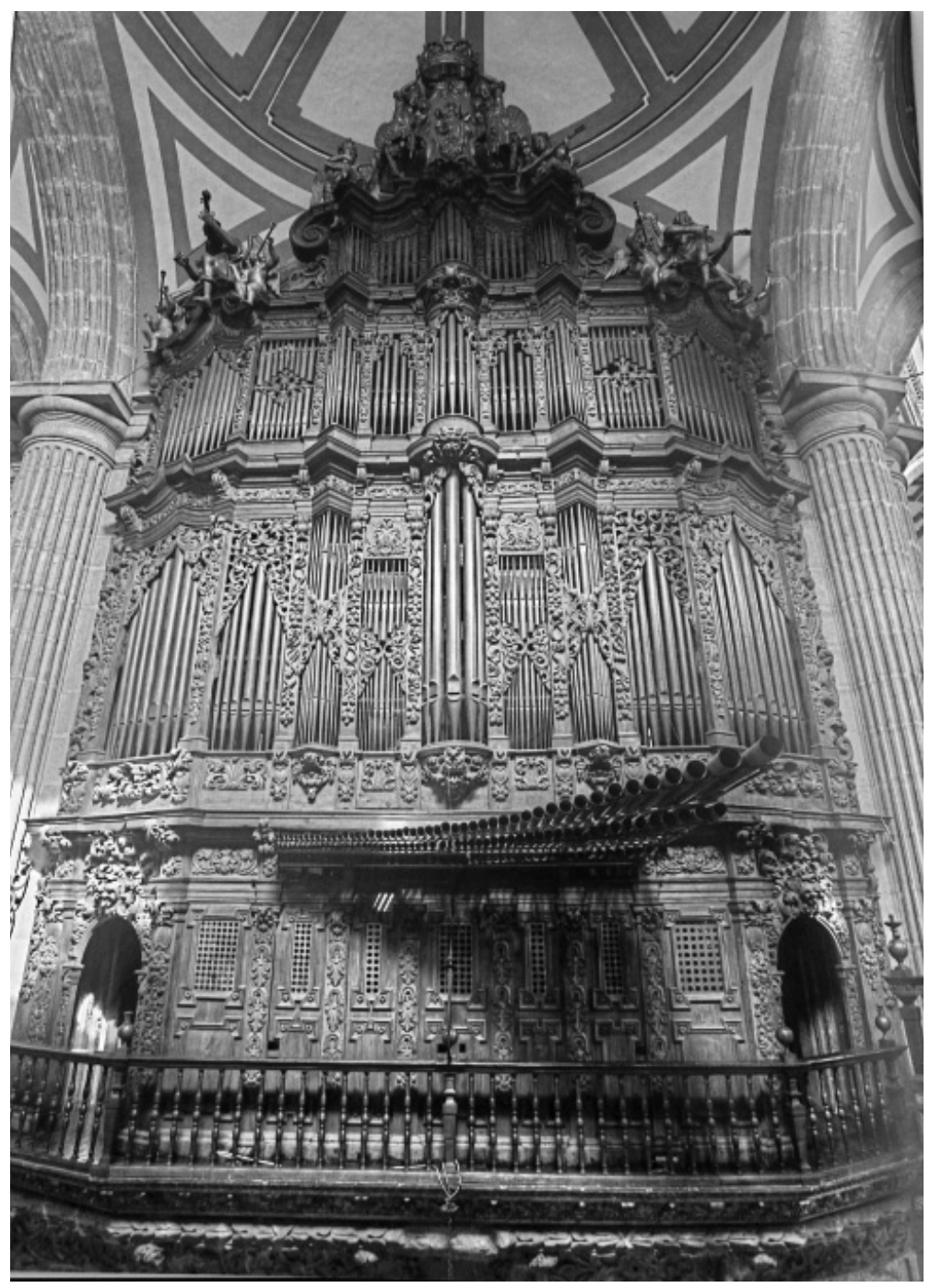

Imagen IV: Órgano de la Epístola, fachada nave oriente 
Confundir el Rococó con el Barroco Tardío se debe a esa visión superficial de las formas; todo lo que parece complicado y lleno de curvas se llama propiamente Barroco, así que el Rococó se confunde con el Barroco en esa sopa espesa de formas. Pero realmente el Rococó es otra cosa, incluso diría, muy distinta. Tampoco es una época determinada sino que convive con otros espíritus como el Protorromanticismo y los gustos exóticos, y con su gran enemigo: el Neoclásico. ${ }^{10}$

El hecho de que en la decoración de las cajas se hayan usado conchas perfectamente simétricas como alegorías marianas no nos lleva al Rococó, cuya definición formal requiere de la rocalla que es por antonomasia una concha asimétrica, esta ruptura de la simetría es una novedad en el arte ${ }^{11}$.

\section{DISPOSICIÓN FÓNICA}

El manuscrito con la enumeración original de los registros redactada por Nassarre se encuentra en la Quenta General de las obras de Altares, Órganos, Tribunas, Cantería, Ornamentos y Capas $=$ Con los instrumentos de Comprobazión ${ }^{12}$.

El órgano del Evangelio posee actualmente $98^{13}$ registros partidos y el de la Epístola 90; un total de casi diez mil flautas, sonoras y canónicas (mudas); sus flautados principales fueron construidos con base en las 26 quartas o palmos castellanos (21 cms., por palmo), es decir los 16 pies convencionales, que resulta una dimensión poco frecuente en nuestra organería virreinal; el llamado órgano entero. Con experiencia y tino, Nassarre insistió en emplear en el nuevo órgano del Evangelio materiales de óptima calidad. Usó madera de cedro blanco viejo de Orizaba y madera clara, sin nudos, de ayacahuite, de probada resistencia y calidad; estaño fino y plomo de los reales de minas novohispanos; pieles curtidas de oveja de los fríos valles de Toluca; clavos, herrajes, tablería, así como cerraduras, tirantes de registros, contras y teclados taraceados en hueso, cuerno y maderas preciosas. Lo mejor que producía el reino.

10 PÉREZ VILLALTA (2010): 15.

11 Ibid.: 34-35. "Una rocalla puede empezar teniendo algo de raíz arbórea entre rocas, seguir con algo parecido a lo vegetal para, de pronto, pasar a ser una cornisa de flechas y ovas que se convierte en algo parecido a una ola con salpicaduras para ser, al final, bambúes entre nubes".

12 Fábrica Material, (ACCMM), 1737, Libro 5, ff, 10, 11, 12. Publicada en el Apéndice XIV, en GUZMÁN BRAVO, 2013: 344-347.

13 Ver "Tabla de Registración" a continuación.
Antes de comenzar su nuevo instrumento, don José Nassarre se hizo cargo de desmontar el viejo órgano de Diego Sebaldos (1656), del cual elogió la calidad del metal y las maderas empleadas. También hubo que darle una "mano de gato" al órgano de Sesma-Sans (1695), que quedó en perfecto uso en la Epístola antes de su total remodelación en 1736, para no dejar al coro y cabildo sin órgano los meses que durarían las obras.

El gran órgano posee las innovaciones y registros conocidos en su momento por las escuelas castellana y aragonesa, con el clásico cuerpo de principales basado en duplicaciones armónicas de los flautados de coro y nave, un nutrido grupo de nasardos y cornetas, lengüetería de batalla en ambas fachadas, flautas particulares y registros característicos, contras de metal y de madera, bombardas, cornetas expresivas en caja de ecos y 70 años después le fue adicionado un medio teclado solista con cinco registros de mano derecha en caja expresiva; dos de flauta y tres de clarines, todos con eco en forma de corneta.

Los órganos fueron concebidos por Nassarre bajo el concepto de la policoralidad barroca; los ecos, juegos de contraste entre las caderetas y el órgano mayor, respuestas desde los diferentes pisos de las fachadas y las naves, la dotación de clarines tendidos horizontales con las cornetas interiores en eco, la perspectiva real de sus múltiples fuentes sonoras, todo convoca a la policoralidad que era el estilo de composición que privó durante más de un siglo, representado en las misas, motetes y villancicos de los maestros de capilla del barroco novohispano desde Francisco López Capillas (1654-1674), Joseph de Agurto y Loaysa (1676-1688), Antonio de Salazar (1688-1715), Manuel de Sumaya (17151739) hasta el inspirado magisterio de Ignacio Jerusalem (1750-1769). Los múltiples coros angélicos pintados a fines del siglo XVII por Cristóbal de Villalpando y Juan Correa para la Sacristía Mayor, requieren esa perspectiva espacial contrastada en timbres y dotaciones instrumentales; solistas, coros y ministriles angélicos en flagrante concordancia con la concepción fónica del órgano y con las necesidades de ejecución de la música policoral.

El nuevo órgano contó con pedales para accionar las bombardas de madera y contras abiertas (grandes tubos de 26 palmos, accionados por pisas de madera enganchadas a una extensión de contra octava del teclado principal, rehechas en la reforma de don Mariano Pérez de Lara. 


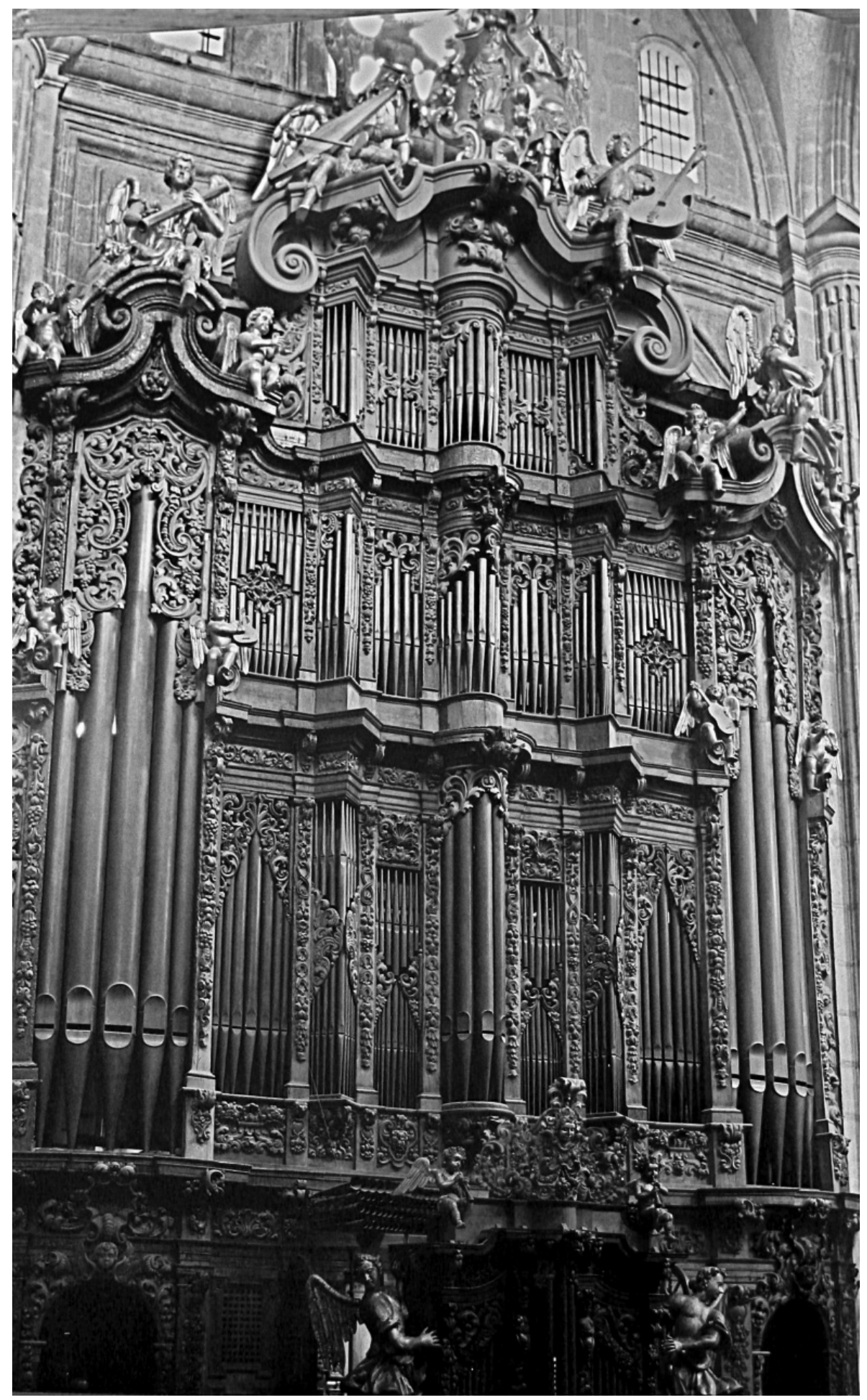

Imagen V: Órgano del Evangelio, fachada coro. 


\section{REGISTRACIÓN DE LOS ÓRGANOS GEMELOS DE JOSEPH NASSARRE (1734-1736) ${ }^{14}$}

\begin{tabular}{|c|c|c|c|c|c|c|c|}
\hline \multicolumn{8}{|l|}{$\begin{array}{l}\text { Evanpe los } \\
\text { Orpane Mayor }\end{array}$} \\
\hline Baja(C,D.e) & & Tiples (cas-d) & & Bajos (C-e) & & Tiples(cas-d) & \\
\hline Pautado Maycr & 16 & Flatado Mayor & 16 & Furado Migor & $\mathbf{8}$ & Flutado \& 26 (madtra) & 16 \\
\hline $\begin{array}{l}\text { Vantado } \\
\text { Vlantado (Nove) }\end{array}$ & 8 & $\begin{array}{l}\text { Hartado } \\
\text { Flatado (Nove) }\end{array}$ & $\begin{array}{l}8 \\
8\end{array}$ & $\begin{array}{l}\text { Vuriado (madera) } \\
\text { Vuntadb Nove) }\end{array}$ & $\begin{array}{l}8 \\
8\end{array}$ & $\begin{array}{l}\text { Funtado Mayce } \\
\text { Flatiabo (Nve) }\end{array}$ & $\begin{array}{l}s \\
s\end{array}$ \\
\hline Violden & 3 & Vialda & 8 & Vialca & $\boldsymbol{s}$ & Victón & 3 \\
\hline Octra & 4 & Hata Traersa & a & Octuram & 4 & Punta Traersa & n \\
\hline $8 \mathrm{Nar}$ and & 4 & Octava & $\boldsymbol{E}$ & Octava Nurada & 5 & Octar & 4 \\
\hline Eppigueta & 4 & 8 Norarda & $\boldsymbol{x}$ & Hpigurta & 4 & $8^{\circ} \mathrm{Nar}$ anda & 4 \\
\hline Docra & $22 / 3$ & Espigurta & 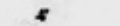 & Docena Cina & $22 / 3$ & Expigueta & 4 \\
\hline 12 Nonzand & $22 / 3$ & Docena & $222 / 3$ & Docena Neserndh & $22 / 3$ & Docena & 2223 \\
\hline Quincraa & $z$ & 12 Naranda & $222 / 3$ & Pabiotete ctnico 12 & $22 / 3$ & 17 Norada & $22 / 3$ \\
\hline 15. Norimh & $\bar{z}$ & Quincern & $z$ & QuincenaClara & $z$ & Quincrea & $z$ \\
\hline Epigueta & $z$ & 15 Naranda & $z$ & Ouinocena Naranda & $z$ & 15. Noradh & $z$ \\
\hline 1T Norach & 13ys & $\pi \cdot$ Naranda & rys & Diez y setena Clan & ryss & 17 Norads & rys \\
\hline Diexy novena & $11 / 3$ & 10* Narand & rass & Diez y sekna Nururdh & rys & $17 \times$ Neraxdn & rass \\
\hline Veinte docena & $\mathbf{r}$ & Dixz yoven & $\mathbf{r u / 3}$ & Diez y novenu Clara & $\mathbf{r} 1 / 3$ & Diea y novena & $\mathrm{r} 1 / 3$ \\
\hline 22 Noxh & $\mathbf{r}$ & Leno & $\mathbf{v}$ & Veintidocena clum & $\mathbf{v}$ & Inas & $\mathbf{v}$ \\
\hline Itao & $\mathbf{v}$ & Cimbola & & 1 eno & $\mathbf{N}$ & Crmbula & in \\
\hline $\begin{array}{l}\text { Cimbula } \\
\text { Sotmectinbata }\end{array}$ & $\begin{array}{l}\mathbf{~ v} \\
\text { min }\end{array}$ & $\begin{array}{l}\text { Sobrecimbala } \\
\text { Comxta Mana }\end{array}$ & mu & $\begin{array}{l}\text { Cimbela } \\
\text { Sobrecinbela }\end{array}$ & $\underset{\mathbf{m}}{\mathrm{m}}$ & $\begin{array}{l}\text { Soluedimbala } \\
\text { Corneta Mraa }\end{array}$ & vu \\
\hline Trampens Real & $\bar{g}$ & $\begin{array}{l}\text { Cormetaen Hoo } \\
\text { Tolcsana } \\
\text { Trompeas Beal }\end{array}$ & in & Trompela Real & $\overline{8}$ & $\begin{array}{l}\text { Corneta en Bico } \\
\text { Tolosama } \\
\text { Trampera Reat }\end{array}$ & $\begin{array}{l}\text { vn } \\
\text { m }\end{array}$ \\
\hline \multicolumn{4}{|c|}{ 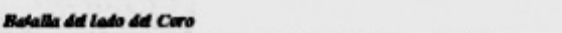 } & \multicolumn{4}{|l|}{ Bdelle ad lafo ed Caro } \\
\hline $\begin{array}{l}\text { Baponcillo } \\
\text { Clerte is } 15\end{array}$ & 8 & 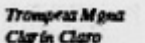 & $10^{\circ}$ & Ortos (coro) & 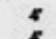 & Trampesa Mpena & $16^{\circ}$ \\
\hline arto & 8 & Carin Camparia & $z$ & Crimes $15^{\circ}$ (corv) & $z$ & Clarin Claro & 8 \\
\hline & & Carin Campana & 8 & & & Clarin Claro & $g$ \\
\hline & & $\begin{array}{l}\text { Obar } \\
\text { Clarimest }\end{array}$ & $\frac{5}{16}$ & & & $\begin{array}{l}\text { Otwer } \\
\text { Chrimfa }\end{array}$ & $g$ \\
\hline \multicolumn{2}{|l|}{ Beballa de la None } & & & Bdalla de laNave & & & \\
\hline Mapoencillo N & 5 & Trompess M/gest & 16 & Hajcecalo (nave) & 16 & Trampera Mpan & $16^{\circ}$ \\
\hline $\begin{array}{l}\text { Carin en } 15 \% N \\
\text { CWirimian } N\end{array}$ & $z$ & $\begin{array}{l}\text { Carin Caros } \\
\text { obure }\end{array}$ & $\stackrel{s}{z}$ & $\begin{array}{l}\text { Cirth cturs (nare) } \\
\text { Otex }\end{array}$ & 8 & $\begin{array}{l}\text { Clarin Claro } \\
\text { obuer }\end{array}$ & $\begin{array}{l}g \\
g\end{array}$ \\
\hline \multirow{2}{*}{\multicolumn{2}{|c|}{$\begin{array}{l}\text { Codereta } \\
\text { Interior Evjos }\end{array}$}} & \multirow{2}{*}{\multicolumn{2}{|c|}{ Interior Tiples }} & Condenta & & & \\
\hline & & & & Interior Bujos & & Interior Tiples & \\
\hline Violón & $\mathbf{z}$ & Fartado & 8 & Violken & 8 & Flatado & $\mathbf{z}$ \\
\hline Octora & 4 & Vialda & 8 & Octara & 4 & Viction & $\mathbf{s}$ \\
\hline Dexy yeta & $13 \times 5$ & 8 Nourda & 4 & Docena & $222 / 3$ & Octora & 4 \\
\hline Diezy novena & $11 / 3$ & Docena clura & $222 / 3$ & Diezy sekena & rass & Docrnactarn & 2223 \\
\hline $\begin{array}{l}\text { Unoo } \\
\text { Cimbula }\end{array}$ & $\underset{\mathbf{m}}{\mathbf{N}}$ & $\begin{array}{l}\text { Diez y setena } \\
\text { IFno }\end{array}$ & rys & $\begin{array}{l}\text { Diez y aovena } \\
\text { Ikno }\end{array}$ & $\begin{array}{l}\mathrm{r} 1 / 3 \\
\mathrm{~m}\end{array}$ & $\begin{array}{l}\text { Irao } \\
\text { Tolocan }\end{array}$ & m \\
\hline Maponcilito & 8 & Cemben & $\mathbf{m}$ & Bapioncillo & $x$ & Corneta & vu \\
\hline & & Conxta & va & & & Clarin & $g$ \\
\hline \multicolumn{2}{|l|}{ Exterior Bajas } & \multicolumn{2}{|l|}{ Euterior Tiples } & Futeriner Raios & & Puterier T-le & \\
\hline Octira & 4 & Octan & 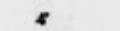 & Octara & 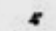 & Pabiolet & 4 \\
\hline Quinarna & $z$ & Quincena & $z$ & Quincena & $z$ & Quincras & $\boldsymbol{r}$ \\
\hline Veinte y docena & $\mathbf{r}$ & Dier y movem & $\mathbf{r} 1 / 3$ & Veintey docraa & $\mathbf{r}$ & Dier y extena & rys \\
\hline & & Conzta Mana & $\mathbf{v}$ & & & Corneta Myaa & $\mathbf{v}$ \\
\hline Pedal (C.I) & & Eco Tples (cked) & & Pedal (C-El) & & & \\
\hline Contras abiertas & 16 & Vialćn & 8 & Contras abiertas & 16 & & \\
\hline Contras abiertas & 8 & Dooem & $222 / 3$ & Contras abiertas & $\boldsymbol{s}$ & & \\
\hline Contras abiertus & 4 & Quincena & $z$ & Contras abiertas & 4 & & \\
\hline Nomburda & $16^{\circ}$ & Diez y aovern & $r 1 / 3$ & Bombenda & $16^{\circ}$ & & \\
\hline Bomburdr & $s$ & CArimstr & 16 & Bandanda & 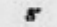 & & \\
\hline Bomburda & 4 & Vialines & $r$ & Bambarda & 4 & & \\
\hline \multicolumn{2}{|l|}{$\begin{array}{l}\text { Degintros de adorno } \\
\text { Cauias } \\
\text { Pajmitos } \\
\text { Tambor } \\
\text { Trmbel } \\
\text { Campanas }\end{array}$} & \multicolumn{2}{|c|}{ 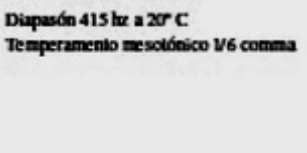 } & \multicolumn{4}{|c|}{ 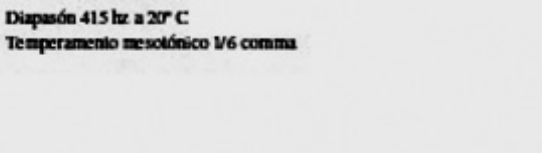 } \\
\hline
\end{tabular}

14 Agradezco al maestro Óscar Laguna del taller de Gerhard Grenzing en el Papiol, Barcelona, restauradores de los órganos gemelos de catedral de México, por la actualización de esta información (Noviembre del 2015). 
Antonio Pérez de Lara (1801), quien también fue autor del tecladillo de 27 notas, recitativo de mano derecha, que acciona una caja de expresión con sus mixturas (1808), una de las diferencias que existen con el otro instrumento.

A más de lo dicho tiene un medio teclado à la mano derecha q., le agregó mi difunto padre, con cinco registros, dos de flauta y tres de clarines, todos con eco en forma de corneta ${ }^{15}$.

Las múltiples perspectivas sonoras de los órganos gemelos se debe a que dirigen sus flautados verticales orientados desde diversos puntos de la caja y sus clarines, trompetas, chirimías y bajones externos horizontales, cornetas internas o en cajas expresivas, dirigidos a puntos diversos del ámbito espacial catedralicio; emiten sus timbres desde diferentes alturas y posiciones logrando sonidos con perspectiva y planos con relieves dinámicos y tímbricos de cercanía inmediata, ecos lejanos y efectos sorpresa, superioridad indiscutible sobre los electrófonos que comprimen sus sonidos en bocinas con referencias espaciales virtuales y no de perspectiva sonora real.

Cuando los instrumentos de Nassarre estuvieron acabados a fines de 1736, la revisión minuciosa y los dictámenes de organistas expertos, establecieron desde entonces un protocolo tradicional de recepción, juicio y dictaminación en la Catedral de México.

\section{EL RITMO ARMÓNICO Y LA SIMETRÍA DE LAS PROPORCIONES}

Talladas en las mejores maderas del Reyno, las cajas que encierran los mecanismos, secretos, fuelles y cañutería de los órganos monumentales de Catedral, se encuentran entre los proyectos constructivos más ambiciosos de la organería barroca mexicana. Rigen la composición de los cuerpos tallados los principios armónicos de las proporciones pitagóricas en boga entre los neoplatónicos novohispanos del barroco; la arquitectura como armonía sonora a través de la simple aritmética. La propia Sor Juana Inés de la Cruz, sin ser muy perito en la Música, admira los primores de las proporciones musicales que hay en tantos lugares ${ }^{16}$ :

15 Nómina de las mixturas 16 de febrero de 1821, (ACCMM), Actas de Cabildo, Libro 69 de acuerdos del Illmô. y V. Cabildo Metropolitano de México, fol. 316r.

16 DE LA CRUZ (2005): 18. Pues sin ser muy perito en la Música, ¿Cómo se entenderán aquellas proporciones musicales y sus primores que hay en tantos lugares, especialmente en aquellas peticiones que hizo a Dios Abraham por las Ciudades, de que si perdonaría habiendo cincuenta Justos, y de este número bajó a cuarenta y cinco, que es
La traza de sendas fachadas que miran al coro, hecha a compás según las reglas de la proporción y simetría barrocas, plantea cuatro cuerpos horizontales flanqueados por dos grandes platabandas o calles, de doble altura, que contienen cada una cinco tubos de 26 palmos castellanos de las contras y establecen el ritmo de 9-7-5 de las platabandas, que se estrechan al subir, creando una armónica perspectiva óptica, coincidente con las proporciones aritméticas pitagóricas que aseguran la resonancia acústica de la caja como resultado de la exacta proporción, secreto del organero.

Los cuerpos de los órganos están diseñados de acuerdo con las medidas clásicas indicadas por Fray Pablo Nassarre en su Escuela Música ${ }^{17}$-que corresponden a la proporción aritmética y musical de los intervalos perfectos consignados por Pitágoras y considerados por los neoplatónicos como punto de partida de la eufonía armónica; octava, quinta y cuarta; Es decir que la relación de la altura total del órgano respecto a su anchura es de 2:1, (Octava); la de los cuerpos verticales con los horizontales de 3:2, (Quinta); y la relación de la parte superior de la caja con el basamento de ésta es de 4:3, (Cuarta y Doble Octava); todas las otras proporciones relacionadas con la altura y anchura del castillo central y con los demás elementos de la caja están determinadas con la ayuda del compás:

La superioridad de los artesanos clásicos con relación al artesano moderno viene del hecho de que conocían el manejo del compás para establecer todas las proporciones del órgano ${ }^{18}$.

El diseño propuesto por Nassarre y aprobado por el Cabildo en mayo de 1734 comprende la gran caja de cuatro pisos con doble fachada que habría de llenar totalmente, a lo ancho y alto, el espacio entero del arco, con robustas cornisas sosteniendo una orquesta completa de veintiséis ángeles de tamaños diversos, ejecutando corneta, chirimía, flauta, vihuelas de mano y arco, bajón, etc., los últimos ángeles coronan a la Virgen, al centro del gran arco. La pequeña fachada de tres castillos de la cadereta externa que sirve al coro, flanqueada por dos arcángeles mozos de tamaño más que natural también fue tallada por el propio Nassarre. Las pilastras que separan las platabandas y las celosías que cierran los espacios libres de

sesquinona y es como Mi a Re; de aquí a cuarenta, que es sesquioctava, y es como de Re a Mi; de aquí a treinta, que es sesquitercia, que es la del Diatesaron; de aquí a veinte, que es la proporción sesquiáltera, que es la del Diapente, de aquí a diez; que es la Dupla, que es el Diapasón; y, como no hay más proporciones armónicas, no pasó de ahí. Pues ¿cómo se podrá entender esto sin música?

17 NASSARRE, 1980.

18 HOPE, Alfred, Das Wiederentdeckte Werkgemeimnis des Deutschen Orgelbaus, citado por RAINOLTER, 1985: 17 
los flautados, se decoraron con imaginativos roleos vegetales, conchas, perlas y otros símbolos marianos, enmarcando horizontal y verticalmente a la cañería de los flautados principales de fachada. La gemela disposición de sus seis fachadas -dos monumentales de coro más las dos pequeñas de la cadereta y dos que dan sobre las naves ambulatorias- evocan galeones con el velamen desplegado y los cañones tendidos de su trompetería de batalla, la requerida artillería defensiva.

La proporción clásica se alcanza gracias a una precisa relación entre sus cuatro cuerpos horizontales y las platabandas verticales $(9,7,5)$, que ascienden hasta la clave del gran arco, en el que la Virgen está siendo coronada.
El diseño original establece una proporcionada y paulatina disminución del tamaño de las flautas, hasta llegar al tercero y cuarto cuerpo en el que se encuentran las llamadas flautas canónicas (mudas) algunas colocadas invertidas para completar la simetría ascendente de los flautados de fachada. Se establece una perspectiva de elegante armonía, con airosas cornisas en sus dobles fachadas donde se posan cuatro orquestas con una dotación total de cincuenta y dos ángeles músicos, en franco desafío a las leyes de gravitación universal, barroca osadía que aligera la corporeidad de estos robustos personajes y sugiere el vuelo de la música celestial.

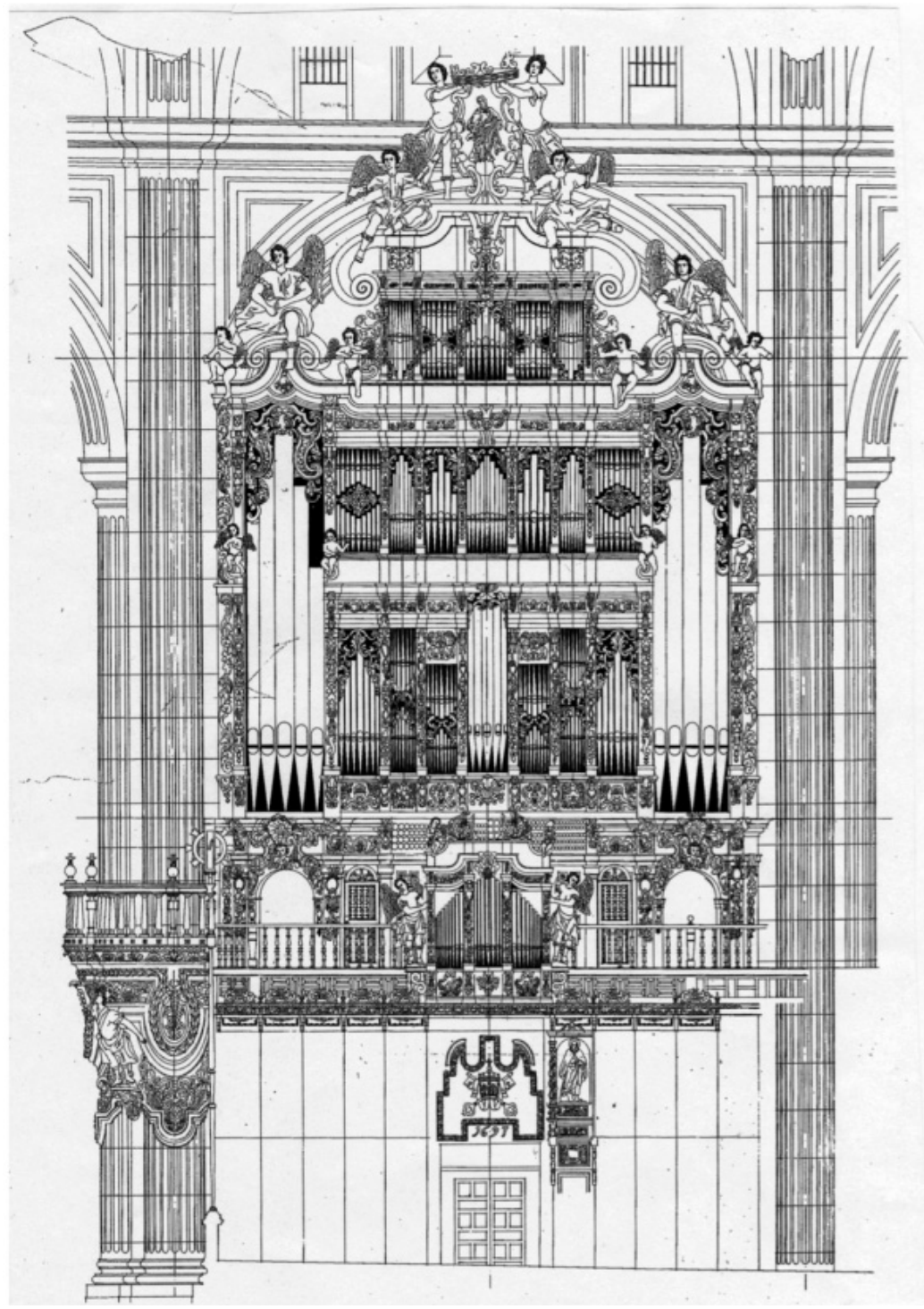

Imagen VI: Órgano de la Epístola fachada coro 


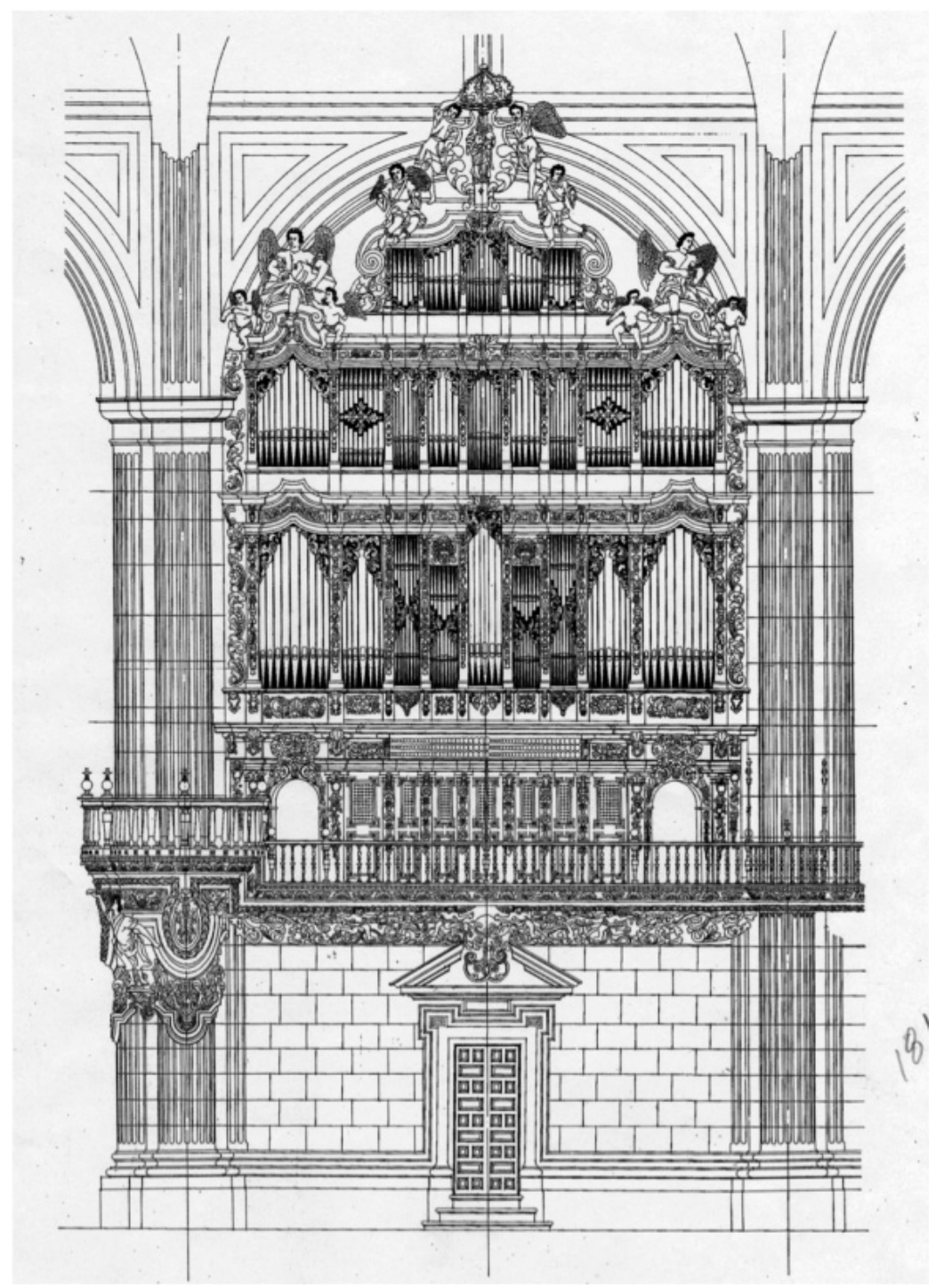

Imagen VII: Órgano del Evangelio fachada nave poniente.

\section{LOS ÁNGELES MÚSICOS}

Las dos enormes cajas fueron labradas con primor y pronto se vieron colmadas con una orquesta de 52 ángeles músicos, otros ángeles cantores y otros más que coronan a cada una de las cuatro vírgenes que rematan cada fachada.

Las advocaciones de la Vírgen son cuatro: Órgano poniente coro; Virgen de la Asunción, fachada nave poniente; Virgen de Guadalupe, Órgano oriente coro; Virgen del Pilar y fachada nave oriente; Virgen de los Remedios.
Se observa la protocolaria distribución; la Virgen de la Asunción, patrona titular de catedral en la fachada principal del Ier. órgano, la Virgen de Guadalupe, cuyo culto apenas se popularizaba, sobre la nave procesional poniente. En la tribuna de la Epístola siempre existió un órgano aragonés; desde el primero de Jerónimo de Aragón (1617), trasladado de la sacristía en 1667 con motivo de la consagración de la catedral, el de Sesma-Sans-Rojas de 1695 y el II $^{\circ}$ de Nassarre de 1736, todos los constructores ligados a este órgano acusan origen aragonés por lo que no resulta raro que en el 
remate de su caja se encuentre la Virgen del Pilar y al lado procesional oriente la saludable Virgen de los Remedios, popular entre los enfermos y menesterosos que deambulaban en la nave.

Los ángeles músicos que ascienden hasta coronar a las vírgenes, fueron esculpidos para adorno de las cajas en cuyas cornisas se encuentran con varias proporciones, diversas actitudes y poses gestuales que indican el tipo de ejecución adecuada para los instrumentos musicales que cada cual lleva.

Estos instrumentos aunque se consideran votivos o canónicos, es decir, mudos, proceden de los períodos prehispánico (teponaztle); clásico (lira, arpa, tímpano); gótico (rabel, tromba marina, gaita); renacentista (tambor de caja, vihuelas de mano y de arco, laúd, arpa, corneta, clarín, bajón, chirimía, pífano) y barroco (violín, oboe, fagote, violoncelo, guitarra). Conjuntos eclécticos de atrevida fusión que responden a la concepción policoral de situar, en puntos espaciales diversos, a los emisores sonoros, coros, solistas e instrumentistas ${ }^{19}$.

Los instrumentos musicales, varios ángeles y muchos tubos originales, desaparecieron a consecuencia del misterioso incendio del 17 de enero de 1967. Sólo algunos de los ángeles más inaccesibles se salvaron, la mayoría perdió el dorado original y cada órgano posee un total de 26 ángeles músicos ${ }^{20}$ más 8 ángeles cantores que coronan a cada una de las dos vírgenes en cada órgano y 4 arcángeles más que sostienen las caderetas, 64 en suma. 16 ángeles tocan sus dorados instrumentos hacia el coro y diez hacia la nave en cada órgano. Los cuatro ángeles que sostienen a las caderetas de ambos órganos así como los que coronan a la Virgen, no tañen instrumentos.

Los instrumentos de la orquesta celestial se encuentran en la siguiente clasificación ${ }^{21}$ :

\section{Idiófonos y membranófonos:}

Teponaztle

Címbalos (platillos y triángulo) Tambor de parche (redo-

blante, caja)

\section{Aerófonos:}

Pífano

19 Bioscopio 1892c, Fotos de Guillermo Kalho (1909), Salvador Moreno (1964), José Antonio Guzmán (1974), Don Allen (1986).

20 Se ha sugerido una referencia numerológica al 52, número de los años del siglo en el Xihupohualli (cuenta de los años en el calendario mexica), cada ángel representaría un año del siglo y la Virgen al Fuego Nuevo.

21 Basado en la clasificación de instrumentos musicales postulada por HORNBOSTEL Y SACHS (1914).
Flauta de pico

Flauta traversa

Chirimía Oboe

Bajón

Fagote

Clarín

Corneta

Trompeta

Corno

Gaita

\section{Cordófonos punteados:}

Lira Vihuela Guitarra Mandola Laúd Arpa

\section{Cordófonos de arco:}

Violín (fídula, rebec, rabel) Viola da braccio

Vihuela de arco (viola da gamba, violonchelo) Tromba marina

Zanfonía (violín de rueda, lira mendicorum, chanfoña o zampoña)

Hay que recordar que los ángeles fueron acabados en pan de oro por Francisco Martínez, maestro pintor y dorador, vecino de esta ciudad, que cobró 350 pesos de oro de minas por los 26 ángeles de cada órgano.

Se develaron en la fiesta patronal de la Virgen de la Asunción, el 15 de agosto de 1736.

\section{LOS FLAUTADOS DE FACHADA}

El análisis descriptivo de la iconografía escultórica por último habrá de considerar la cuestión cromática de los flautados de fachada, brillantes protagonistas de enfoques y reflejos que, en el momento de su estreno era... tan fina la cañutería, que de puro fina, parece plata...como se lee en el prolijo y detallado dictamen de Juan Télles Xirón ${ }^{22}$, organista mayor de la catedral en el momento de la recepción de los órganos en octubre de 1736.

En la restauración de Flentrop (1975), se tomó la decisión arbitraria de aplicar al flautado de fachada un barniz pardo para oscurecer los tubos con un tono plomizo postincendio. Desafortunada elección si tomamos en cuenta que la composición de la cañutería principal es de $92 \%$ estaño y sólo un $8 \%$ plomo, bruñidos los tubos para que el estaño luzca. Resulta más correcto e interesante cromáticamente el

22 Dictamen del organista Juan Télles Xirón (1736), (ACCMM), en la Quenta General de las obras de Altares, Organos, Tribunas, Cantería, Ornamentos y Capas $=$ Con los instrumentos de Comprobazion. Fábrica Material, libro 5, Año de 1737 ff. 41r - 42v. 
que los tubos revelen su fina composición, devolviéndoles su brillo natural, con la pátina del tiempo, recobrando el claroscuro barroco. Sin embargo a la fecha no se ha devuelto ni su color ni su decorado a las bocas de las flautas; la última restauración documentada es de 1801 . Todas las bocas de los caños de las cuatro fachadas estaban orladas por unos mascarones color rojo y oro, con caras monstruosas llamadas figurones $^{23}$. El modelo se puede ver claramente en el Bioscopio de ca.1892 y en las fotos de Guillermo Kalho (1909), Salvador Moreno (1964), José Antonio Guzmán (1974) y Don Allen (1986).

Se tomó la prolixa operación de limpiar todas las flautas de ambas fachadas, cuyas embocaduras se pintaron dexándolas brillantes, y vistosas como si acabaran de hacerse, sin que por esta superficial operación, alterasse, ó perjudicasse en cosa alguna, la fábrica material de estos cañones, ó a su sonido, ó tono, por que si bien se considera, el sonido no resulta de la parte exterior de ellos,sino de su cóncavo, ó interior longitud y latitud ${ }^{24}$.

Devolverle sus figurones e iluminarla adecuadamente constituye una mejora significativa que resaltaría la correspondencia armónica entre la luz, el color y el sonido. Es una manera de preservar y difundir la riqueza iconográfica escultórica y sonora que poseen las cajas de los órganos, de gozar integralmente el patrimonio cultural de México.

En la presente restauración no se buscó recobrar el brillo del estaño en los flautados principales de las cuatro fachadas, que correspondería al taller de Grenzing, ni la restitución de los mascarones de boca que debieran ser pintados, en negro rojo y dorado, por los restauradores de la caja (INAH), ya sobre el caño limpio.

La hechura y pulido de los tubos con soldaduras de calidad particular, caños canónicos o mudos geométricamente dispuestos y el interesante trabajo en los flautados prestantes verticales contrastados con las trompetas en artillería horizontal tendida. Todo dispuesto para crear juegos de contraluz y reflejos, de plenitudes sonoras, ecos, y sólos distantes o en cajas de expresión; il ciaroscuro barocco ilumina la sonoridad policoral del instrumento. La aclarada cañería, alojada en las quellas, petos, castillos y platabandas, entre elegantes

23 Existen algunos ejemplos de figurones en varios órganos de la República (Santa Ma. Magdalena, San Martín Texmelucan, San José., Museo Bello, Puebla; San Jerónimo Tlacochahuaya, San Andrés Zautla, Yanhuitlán, Oaxaca; San Agustín, Sta. Ma. Cuitzeo, Michoacán; Sta. Prisca en Taxco; San Felipe Neri, La Compañía, Guanajuato; Sn. Francisco y Sn. Antonio en Querétaro, entre otros).

24 Informe de Dn. José Gámez, nov.1801, ACCMM, Fábrica Material,Caja 3, Expediente 5, fol. 7v. cornisas y una orquesta de ángeles músicos, recién dorados y restaurados, recobraría el necesario juego de luz y sombras aplanado por la oscuridad del barniz ahumado y por el tacaño ahorro de una iluminación adecuada.

\section{FUNCIÓN SOCIAL}

Desde un principio, se contempló la necesidad de darle un sentido cultural a la tan esperada restauración de los órganos de la Catedral Metropolitana de México por tratarse de los instrumentos históricos más importantes del continente americano, fuente valiosa de información y conocimiento de la música novohispana y de su contexto. Es momento de pensar en el uso y aprovechamiento de dichos instrumentos para promover el desarrollo y aprecio del arte organístico, con calendarios de uso litúrgico y de uso cultural; horas de estudio, presentaciones y conciertos, claros criterios de acceso, credenciales, permisos, etc. Rescatar cuatro horas diarias de uso cultural enriquecería considerablemente el nivel de aprecio a los órganos y a sus magníficos repertorios.

Esto requiere de la presencia activa de los organismos de cultura para racionalizar su uso ya que posibilitan una Ejecución Históricamente Informada de nuestros archivos musicales de los siglos XVI al XIX, lo que resulta invaluable en grabaciones, cursos y conciertos, que recuperan los ricos repertorios del Renacimiento, el Barroco y el Clasicismo ${ }^{25}$ que poseen nuestras catedrales y archivos.

Las características fónicas de estos instrumentos, así como el conocimiento de las técnicas constructivas que condicionan su ejecución (la registración, los medios registros, la lengüetería tendida, la octava corta o completa, el ámbito y respuesta del teclado, los pedales y cárcolas de contras), ofrecen una base inmejorable para contextualizar las ejecuciones ya que el instrumento se convierte en maestro y fuente de información. Los instrumentos históricos restaurados apropiadamente, son capaces de generar circuitos de investigación en varias áreas y especialidades; ejecución, musicología, restauración, organería, historia de la música, etc. y como patrimonio cultural universal, deben poder estar accesibles para los interesados y no confinarse a un subempleo convencional.

25 Hoy en día, en México, el entendimiento y aprecio de los órganos barrocos, de la música antigua y de los repertorios musicales del Virreinato, han merecido mayor atención de intérpretes y público, lo que puede augurar la recuperación de espacios dignos, no sólo en el centro histórico de la ciudad capital, sino en toda la República; una ampliación de la oferta musical de calidad. La organería mexicana es una aportación musical al patrimonio cultural de la humanidad. 


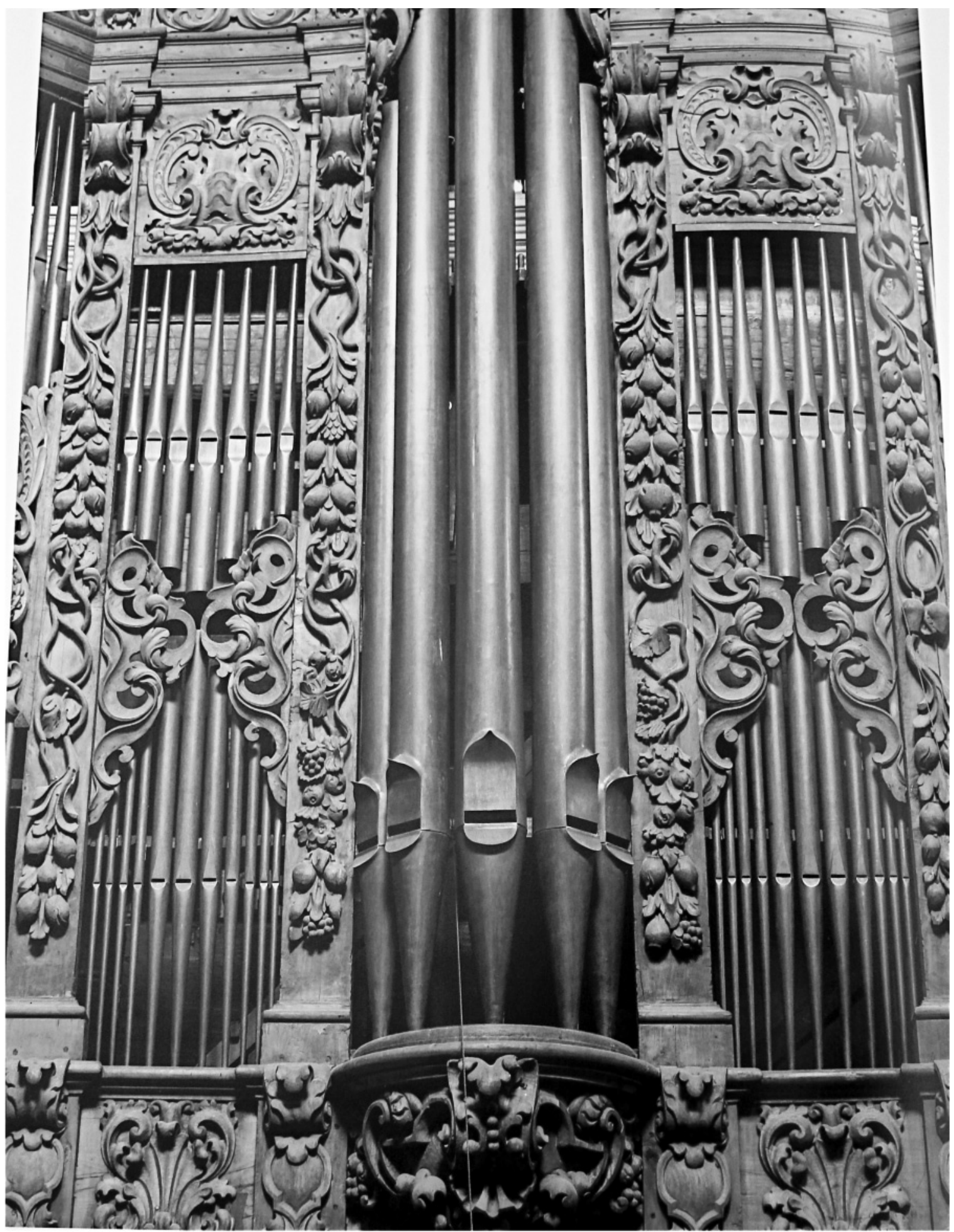

Imagen VIII: Detalle tubería de flautados 


\section{LA EJECUCIÓN HISTÓRICAMENTE INFORMADA (EHI)}

La intención del ejecutante historicista se encamina a buscar elementos contextuales de las obras que le ayuden a analizar, cuestionar y validar musicalmente las decisiones contenidas en un programa al ejecutarlo públicamente. Nuestro gusto personal, capacidades técnicas, cultura musical y criterio selectivo operan como editores.

Quien opta por la EHI, de repertorios del pasado, en instrumentos originales o réplicas veraces, aplicando estos principios musicológicos de ejecución, tiene ante sí un repertorio vasto y de gran belleza. El pasado se reinterpreta, editado y cuidadosamente seleccionado en función de su uso y actuación presente; es un profundo pozo del que extraemos lo que nos resulta apropiado para emocionar a nuestros contemporáneos.

El privilegio de contar con la atención de una audiencia durante nuestra intervención, a veces por el fervor gratuito que inspiran los grandes nombres-, exige ser selectivos y considerados; no todo lo que el pasado guarda resulta significativo y rescatable; hay olvidos bien merecidos, usos y costumbres que deben ser abolidos.

La EHI nos coloca en un punto en el que es posible renovar nuestra relación con el pasado de una forma que antes no fue posible ni necesaria. Ante un pasado musical irrecuperable, nuestra época ofrece un panorama de investigación histórica sin paralelo. Nunca hubo tantas fuentes al alcance, nunca pudimos disponer de un instrumental tan variado en extensas áreas geográficas, nunca antes se pudo consultar o poner en contacto a tantos especialistas, maestros e intérpretes, ni fue tan factible poder escuchar músicas de cualquier región, tiempo y cultura.

La EHI, se basa esencialmente en dos supuestos: el criterio de autenticidad (partituras debidamente transcritas, uso de instrumentos adecuados, aplicación de los criterios de ejecución contextuales, etc.) y el concepto de respeto a las intenciones originales de los autores expresadas con mayor o menor claridad en los tratados y manuscritos que contienen esta música y que permiten acercarse a los lenguajes estilísticos manejados por cada autor a lo largo de su vida creativa.

El ejecutante de estos repertorios habrá de expresarse en los idiomas estilísticos de las obras que estudie. Esto entraña un acercamiento conceptual a las fuentes y partituras, pero también la madura asimilación de los elementos mecánicos y técnicos básicos para relacionarse con los instrumentos históricos y con las dificultades específicas de las obras. Bruce Haynes anuncia en el título de su libro The End of Early Music; A Period Performer's History of Music for the
Twenty-First Century ${ }^{26}$, el planteamiento de nuevas aproximaciones al concepto de Werktreue (fidelidad a la obra) y Urtext (texto original), lejos de la irreflexiva aceptación de tópicos, convenciones y lugares comunes.

Más que nada, Autenticidad parece ser una afirmación de intento. Una ejecución históricamente exacta es probablemente imposible de lograr...pero ese no es el fin. Lo que produce resultados interesantes es tratar de ser históricamente correctos ${ }^{27}$.

Aunque la música sea el elemento primordial del valor de una ejecución, deberá adaptarse a las condiciones particulares del instrumento en el cual se ejecutará; las limitaciones de teclado, octava corta, registros o carencia de ciertos artilugios, podrán condicionar alteraciones, cambios de tesitura o adaptación sonora, con el fin de sacar un mejor partido del instrumento al servicio de la obra musical.

El criterio dictará los márgenes tolerados de adaptabilidad del repertorio elegido, ya que si este fue seleccionado con acierto, se ajustará como guante a los instrumentos históricos. El repertorio organístico manualiter de los siglos XV al XVIII, resulta particularmente adecuado; sobra material de calidad. Además existen obras modernas compuestas o arregladas ex profeso para órganos históricos particulares, pocas, es cierto, como pocos son los órganos adecuadamente restaurados y larga la lista de espera; una condición genera la otra. Asimismo debemos de recordar que este amplio circuito sólo se completa con la ejecución y recepción pública.

Arnold Dolmetsch, pionero en los inicios del siglo XX del "culto a la autenticidad," construyó clavecímbalos, laúdes, violas da gamba y flautas dulces que en su momento fueron referenciales; estaba convencido de que los ejecutantes deberían tocar la música en los instrumentos para los cuáles fue originalmente escrita y de acuerdo a las intenciones de los compositores recogidas en los tratados musicales contextuales.

Es autor de un estudio sobre las fuentes de la ejecución musical, The Interpretation of the Music of the XVII and XVIII Centuries, editado por Novello de Londres, en 1915. ${ }^{28}$ Dolmetsch urgía a los ejecutantes a leer, aprender y tomar en serio lo que los autores antiguos prescribieron para los detalles de la ejecución y usar esa información como base para una recreación imaginativa de las notas en la página. Sin embargo los grados de aceptación de los postulados historicistas y la forma en que cada artista los aprovecha han

\footnotetext{
26 HAYNES (2007). Trad. José Antonio Guzmán.

27 Ibid.;10

28 DOLMETSCH (1969).
} 
sido variables; por ejemplo, su contemporánea, la notable clavecimbalista Wanda Landowska ofrece su versión:

En ningún momento durante el curso de mi trabajo, he tratado de reproducir exactamente lo que los viejos maestros hicieron. Yo estudio, someto a escrutinio, amo y recreo, estoy segura que lo que hago respecto a sonoridad, registración, etc., está muy lejos de la veracidad histórica ${ }^{29}$.

Ella basó sus interpretaciones de Bach, Rameau o Scarlatti en sus ideas personales acerca del carácter esencial de la música, tratando de buscar el espíritu, más que en aplicar los antiguos tratados al pie de la letra. Esto, y el abierto vedetismo de dear Wanda, enfurecieron más de una vez a Dolmetsch.

El público tomó partido a favor de la Landowska, claro está, ya que como intérprete era mucho más convincente que Dolmetsch, quien a su lado resultaba frio y convencional, aunque este esgrimía sensatas razones de calibre.

Thurson Dart, en su libro The Interpretation of Music ${ }^{30}$ ofrece una curiosa mezcla de consejos prácticos para hacer compromisos y una genuina preocupación por la autenticidad histórica. Más de una vez llegó a afirmar que sería ridículo tratar de usar las digitaciones antiguas, ya que podría resultar tan cuestionable como revivir la oftalmología o la cirugía medievales, aunque recomendó conocer las digitaciones para lograr efectos digitales semejantes.

Un saludable agnosticismo parece traslucir en las consideraciones de Arthur Mendel, quien invita a los editores a ser claros y metódicos al reunir y extraer las evidencias tanto de los teóricos como de la música misma:

Lo que se necesita, me parece, no son más artículos dedicados a esta o esa interpretación, o a este o a ese teórico o grupo de teóricos seleccionados arbitrariamente, sino un método ordenado para reunir y extraer evidencias ${ }^{31}$.

Otra fuente contemporánea de gran influencia en los años sesenta fue el notable tratado de Frank Hubbard, 1965: Three Centuries of Harpsichord Making, ${ }^{32}$ que ofrece una extensa documentación sobre las escuelas de construcción de claves y la forma en que están ensamblados, además de proveer planos y referencias preciosas para los constructores en ambos lados del océano. Quizá su mérito mayor fue el de

29 LANDOWSKA (1964): 18.

30 DART (1967).

31 MENDEL (1968): 153.

32 HUBBARD (1965). desarrollar un nuevo estándar en la construcción de clavecímbalos en cuanto a sofisticación, calidad de construcción y variedad de modelos copiados de originales o emulados de diseños antiguos.

Es con base en este tipo de instrumentos que se desarrolla a partir de entonces un boom en la adquisición de réplicas que sustentarán el trabajo de los primeros grupos de música antigua y que brindarán a los intérpretes e investigadores una primera aproximación al instrumento como fuente en sí mismo de valiosas directrices para la ejecución.

Para Robert Donington (1963) ${ }^{33}$, en su clásico tratado sobre la interpretación de la música antigua que fue el Vademécum de toda una generación, partimos por asumir que la música antigua queda mejor realizada si ajustamos lo más posible nuestra moderna interpretación a lo que consideramos -basados en fuentes y evidencias sobrevivientes-, fueron las interpretaciones originales. La doctrina de la autenticidad histórica según Donington, es a partir de los años setenta incuestionablemente respetada, aunque no universal. Observa, por ejemplo, que en conservatorios y escuelas de música convencionales, prevalece el criterio de enseñar y suponer que los nuevos instrumentos y sus técnicas de ejecución son necesariamente superiores a los antiguos (crono centrismo), aunque desde los años 80 la tendencia general se orienta hacia el reconocimiento de que la música antigua es un área específica de la música y requiere sus propias técnicas de ejecución y enseñanza.

Sin embargo el cambio en México no fue pacífico ni gradual, en la mayoría de los casos las peticiones de los estudiantes desembocaron en la contratación de maestros que conocían las prácticas históricas por haber estudiado en Holanda o en Inglaterra (entonces la vanguardia de la música antigua), por haber intervenido en la compra de claves, flautas de pico y violas da gamba, principalmente, o bien en la restauración, copia y en la creación de clases en instrumentos históricos. Luisa Durón y Enrique Aracil de la Escuela Nacional de Música (UNAM), fueron pioneros en México de esta nueva aproximación al repertorio de los siglos XVI al XVIII en el clavecímbalo histórico, en flagrante antagonismo con la escuela de Wanda Landowska, (clave moderno Pleyel), encabezada por su discípula dilecta, la maestra del Conservatorio Nacional de Música, Julieta Goldswartz.

33 DONINGTON, Robert: 1979. "Dedicado a Arnold Dolmetsch, su libro ofreció métodos para entender los estilos, justo cuando más lo necesitábamos...está construido sobre un principio muy efectivo; citar la médula de las fuentes históricas sobre todo asunto relacionado a la ejecución práctica.” HAYNES, 2007; 41. Trad. José Antonio Guzmán. 
En los años sesenta, es dudoso que un movimiento [como la EHI] pudiera haber obtenido credibilidad si no hubiese implicado un elemento de protesta y revolución. ${ }^{34}$

Un poco más tarde músicos como Thomas Binkley y Andrea von Ramm, del Studio der Frühen Musik de Munich, para sus versiones de la música goliárdica de la Edad Media, recurrieron, además de las fuentes escritas europeas, al estudio etnomusicológico de varias tradiciones populares europeas, indoamericanas y del cercano oriente; se aproximaron así a técnicas vivas de ejecución y acompañamiento y sus emotivas interpretaciones resucitaron música "irrecuperable", a través de versiones completamente nuevas y distintas que marcaron un modelo de trabajo interdisciplinario.

Hay muchas ocasiones en las que los ejecutantes buscan la autenticidad histórica detectando reminiscencias y paralelismos en culturas del presente. $\mathrm{El}$ aprovechamiento más profundo de las fuentes etnomusicológicas para sustentar versiones vivas y creativas hace que la recuperación de obras de lejana procedencia temporal resulte fresca y convincente para un público de hoy.

Es indudable la importancia que cobraron los Países Bajos a partir de entonces, ya que un nutrido grupo de virtuosos de alto nivel (Leonhardt, Brüggen, Kuijken, Koopman, etc.), fundaron una escuela de ámbito internacional caracterizada por la elegancia de su ejecución y la cuidadosa atención al detalle. En su momento representaron la contracultura musical y fueron acremente criticados por lo que se consideraban manierismos exagerados (por ejemplo la messa di voce y el estilo retórico elocuente).

Gustav Leonhardt afirma en las notas a su grabación de los Conciertos de Brandemburgo:

Si sólo tratamos de ser auténticos, nunca seremos convincentes. Si uno es convincente el resultado ofrecido dejará una impresión auténtica ${ }^{35}$.

Hoy en día la idea de autenticidad se ve acotada por las convenciones que tolera la experiencia, lo que deriva en que los músicos intérpretes asuman limitaciones y conveniencias de la vida moderna.

Baste de ejemplo el uso generalizado de plectros de delhrin plástico para los claves, en vez de caños de ala de cuervo, estudiar con luz eléctrica y no con velas de sebo,

34 HAYNES, 2007; 41.

35 "If one strives only to be authentic, it will never be convincing. If one is convincing, what is offered will leave an authentic impression." DC. Conciertos de Brandemburgo, (1976), Pro-Arte 2 Pax2001, Trad. José Antonio Guzmán. usar un compresor de aire eléctrico y no fuelleros, etc., por no hablar del radical cambio de función social, acceso a fuentes musicales y posibilidad de elección que nuestros organistas del pasado no tuvieron e, in vece, las particulares condiciones sociales, creencias, conocimientos y habilidades muy suyas, que nosotros no alcanzamos.

Habrá necesariamente convenciones, ajustes y adaptaciones, como los hubo siempre; la posibilidad y características de acceso a ciertos materiales, algunos de carácter privado, que por lo mismo se sujetan a veleidades personales; la ubicación de los instrumentos históricos en iglesias o monumentos nacionales, que casi nunca cuentan con un criterio claro de acceso, etc.; la escasez de instrumentos adecuadamente restaurados y otros condicionantes que más de una vez nos han puesto los pelos de punta.

El pensamiento histórico implica la interpretación de todas las evidencias disponibles, con el mayor rigor crítico. Una ejecución estrictamente historicista, según opina Davies $^{36}$, es aquella en la que los instrumentos empleados son contemporáneos del período de la composición, en la cual la partitura es interpretada a la luz de prácticas estilísticas y convenciones de ejecución del tiempo en que la obra fue compuesta, es aquella en la cual se emplean conjuntos instrumentales del tamaño y disposición, especificadas por el autor. Es importante considerar los aspectos expresivos en la música antigua ya que son impulsos intuitivos que permiten penetrar los significados de la pieza.

Donington opina que la expresión es la reacción entre lo que el ejecutante trae a la música y lo que encuentra en ella. La ejecución (eloquentia, pronunciatio), o lo que Quantz y K.P.E. Bach llamaron Richtiger Vortrag (la bonne expresión), es aquella en la que los dos elementos más importantes de la música son "de toucher \& de plaire"

Muchos factores contribuyeron para el despertar de la EHI, Nicholas Kenyon los resume así:

Interés en la música antigua en sí misma, interés en las técnicas del período, trabajo musicológico, construcción de instrumentos, en suma, un complejo cuerpo de consideraciones académicas y prácticas, que juntas formaron los cimientos para el eventual éxito y popularidad del movimiento ${ }^{38}$.

El fenómeno de la EHI, al menos desde que resultó una fuerza cultural y comercial, no puede ser entendido si no lo referimos a la "condición postmoderna". Taruskin sugiere

36 DAVIES (1987): 40

37 QUANTZ (1752): 2.

38 KENYON (1991): 2-3. Trad. José Antonio Guzmán. 
que esta condición provee una solución (sea "históricamente informada" o no) al reintroducir el elemento humano, echando abajo los grandes discursos sobre la verdad y permitiendo más libertades en la ejecución.

Recordemos que para él, "modernismo" es virtualmente sinónimo de positivismo musical, objetivismo y de abandono a la entrega y al involucramiento personal en la interpretación musical. El intérprete es un instrumento. El modernismo surge del espíritu de entre-guerras en la década de 1930. Mucha de la reciente literatura musicológica tiende a visualizar el modernismo como un dogma consistente de objetividad, positivismo, geometrismo y despersonalización, que descontextualiza y separa al mundo estético de otros aspectos de la vida.

Está claro que para una EHI artística y vital requerimos de un intérprete imaginativo, informado y ejecutivo, que tome decisiones acertadas en el contexto y que se aleje de las convenciones, tópicos y lugares comunes de un intérprete "automático", "transparente", o "sumiso." Por el contrario, ha de poner en operación recursos estéticos y musicológicos para dotar de vida a una partitura notada en forma no prescriptiva, ni absoluta en su acabado.

Mientras Bartok pide en las piezas de su Microcosmos, ejecuciones modernistas absolutamente literales y en un espacio de tiempo cuantificado en segundos, la flexibilidad que exige un Romance glosado, una Tocata de Cabanilles, o un Tiento de medio Registro de Correa, nos enfrenta a otros supuestos y libertades que yacen en esa música y que están en flagrante conflicto con una actitud moderna convencional, transmitida rutinariamente por los conservatorios, que aplica indiscriminadamente la misma gramática musical a las obras de cualquier período, de Conrad Pauman a Luciano Berio.

Las cualidades de una ejecución historicista (con atención al gesto, al fraseo menudo, a las sutiles gradaciones dinámicas e inflexiones, pulido individual de las notas, el tempo rubato, los acentos agógicos, pausas y jerarquía de compases), tienden a oponerse a la predecible y automática regularidad mecánica del estilo convencional moderno, cuyo último logro lo constituyen los pianos mecánicos de Conlon Nancarrow con sus implacablemente perfectos cilindros con Música en pianola (ca. 1965). ${ }^{39}$ Debemos abandonar la idea de que la notación es una receta transparente para la ejecución, algo casi intercambiable con la ejecución misma.

Los compositores organistas, encararon el problema de la notación musical de acuerdo con las convenciones de

39 En el Estudio $N^{o} .19$ de 70 segundos de duración hay exactamente 774 notas staccato distribuidas en siete páginas. la época, un asunto agravado por el hecho de que una gran mayoría estos notables maestros, en el ámbito peninsular, eran ciegos.

Podemos imaginar métodos particulares de trabajo con los "transcriptores" que, de oídas, tomaban las migajas musicales que caían de la mesa, como añora Hernando en el prólogo (1578) de las obras de su padre, el ciego vidente Antonio de Cabezón; recuerdos y apuntes de memorables improvisaciones, obras ya populares como tales, o ejercicios didácticos claramente intencionados, las notaban y probablemente se las tocarían al autor para que con su anuencia se consideraran correctamente anotadas y "reproducibles adecuadamente" ya fuera en cifras de tablatura o en notación en pautas.

El modernismo tiende a valorar la técnica a expensas de la representación de la realidad, idea o estado de ánimo, y así privilegia la competencia y los altos logros técnicos; la visión tradicional de los que buscan la EHI, ha sido la de creer que el

virtuosismo no es el fin primario de una ejecución musical y que una aproximación amateur o rutinaria puede tener sus ventajas...los pioneros del movimiento no colocaban la eficiencia técnica progresiva como premio, el espíritu histórico y la corrección textualestilística, eran más importantes en general $^{40}$.

Esto puede reflejar, en el mejor de los casos, la democratización de la historia, o la liberación de nuestro pensamiento de narrativas preconcebidas acerca del pasado, pero hay que reconocer que bajaron sensiblemente los niveles de ejecución, Butt cree que el beneficio neto supera considerablemente las desventajas ${ }^{41}$.

Ciertamente con el mayor interés que se ha despertado por la ornamentación, la glosa y la improvisación, otras formas de virtuosismo se han desarrollado. La EHI deriva su autenticidad no de su verosimilitud histórica, sino de ser para bien o para mal, un verdadero espejo del gusto de principios del siglo XXI.

No obstante entre más arduamente trabajemos para imitar el pasado, más personal y contemporáneo será el resultado, ya señala hace varias décadas Paul Henry Lang: Es siempre nuestro presente lo que estamos interpretando, pero lo hacemos mirando dentro del pasado ${ }^{42}$.

El sello de "autenticidad" vende bien entre un público desesperado por encontrar algo "original" en esta cultura de copias y realidades virtuales. 
Nicolás Harnoncourt en sus notas a la grabación de las cantatas completas de $\mathrm{Bach}^{43}$ enfoca el problema de esta forma:

De ninguna manera vemos esta nueva versión como un regreso a algo pasado hace tiempo, sino como una tentativa de liberar a esta música de su asociación histórica con el sonido clásico- sinfónico, por medio de la elección transparente y característica de instrumentos antiguos, para encontrar una verdadera interpretación moderna.

Uno de los aspectos más benéficos de la EHI ha sido el hecho de que los mejores ejecutantes han tenido que replantear enteramente sus estrategias interpretativas, cuestionando la asumida expresividad "natural" de la corriente convencional.

Para Dreyfus la práctica de la EHI, se construye sobre la base de la igualdad de sus miembros, sin director, todos compartiendo varias funciones, evitando el virtuosismo, gozando compartir el mundo profesional con el amateur, y así experimentando una relación más cercana con una audiencia semejante y produciendo programas históricamente integrados más que simplemente sensacionalistas ${ }^{44}$.

Este planteamiento resulta natural y congruente en el campo etnomusicológico o amateur urbano, pero dada la competitividad de los mercados de público, entre profesionales hoy día resulta utópico.

A la luz de la justa crítica del literalismo y de la ejecución objetiva muchos instrumentistas han ido desarrollando una actitud más crítica hacia las evidencias históricas, decidiéndose a ejercer su elección libre al usar la información histórica de forma selectiva. Es decir, aplicar el criterio como la guía más personal a la que podemos recurrir.

El ejecutante no sólo pulsa notas, es un artista intelectual que elige una tradición musical para entenderla a fondo y expresarse con ella, para lo cual debe sumar todos los recursos a la mano; análisis musical, metodología de la investigación, historia, organología, composición, improvisación, etc., y aplicarlas integralmente a sus ejecuciones y aún a su vida diaria.

Harnoncourt apoya los argumentos de Hindemith aseverando que cada periodo tiene precisamente el instrumental más adecuado para su propia música. En su imaginación los compositores escuchaban los instrumentos de su tiempo y frecuentemente componían con ciertos ejecutantes en mente. El notable director y clavecinista inglés Trevor Pinnok,

43 Das Kantatenwerk, Vol. I, Teldec, SKW 1/1-2, 1971; 8. 44 DREYFUS (1983): 297-322. siempre escéptico ante la idea de autenticidad histórica, creía firmemente en el poder de los instrumentos antiguos para inspirarnos a crear un estilo de ejecución.

Aun cuando los compositores hayan tenido un papel decisivo en la evolución de los instrumentos musicales, pidiendo mejoras, recursos o sonoridades no conocidas, parten del diseño tímbrico de los medios a su alcance e idean nuevas posibilidades, como el Lautenwerk (clave con cuerdas de tripa) que Bach quiso probar para tener en un teclado las posibilidades de un laúd, las octavas de aumento que requirieron Scarlatti en los claves de Sodi y Beethoven en los fortepianos de Broadwood, las tubas de diversas tesituras que Wagner hizo construir para la Tetralogía, o los Teponaztles sinfónicos, que Carlos Chávez mandó a hacer para su Sinfonía India. Todos parten de algo conocido y asequible en su contexto original, para explorar un terreno que normalmente no es el de un compositor pero que no deja de resultarle atractivo e inquietante.

Cada intérprete crea modelos, asume tradiciones, se adjudica maestros, referencias, puntos de guía, para construir su personalidad musical, única e irrepetible.

La tradición, según Taruskin es acumulativa, múltiple, autorizada, abierta, incluyente, pero sobre todo confusa y desordenada, por lo tanto humana. De lo que se desprende que los hábitos son por definición una adquisición inconsciente, mientras que la tradición resulta de una conciente y deliberada aceptación, uno se inscribe.

Los inventores de la Seconda Pratica, a fines del siglo XVI, no tenían realmente posibilidades de revivir la música de la antiguiedad grecolatina. Como sabemos, el resultado final de sus propuestas no fue la ejecución de la música de la antigüedad, como era originalmente la intención, sino la Nuove Musiche, que no había existido hasta entonces. Paradojal resultado de la indagación del pasado; el descubrimiento de una nueva manera de articular el lenguaje musical que nos llevaría a la creación de un nuevo género, diferente de las tragedias y comedias de la antigüedad clásica; la ópera.

En el caso policultural de México esto es aún más cierto, ya que coexisten en nuestro presente lenguajes musicales y variados instrumentos aún en uso, que nos remiten a fuentes arqueológicas, góticas, renacentistas y barrocas, que ofrecen perspectivas poco transitadas por nuestros investigadores. Pero como todo etnomusicólogo sabe, aún el más sofisticado sistema de notación es incapaz de indicar lo esencial de una transcripción para captar un estilo de ejecución convincente en su contexto.

Es un hecho que el contacto de un músico tradicional con instrumentos originales, réplicas fieles o logradas emulaciones, constituye una revelación sonora a la que un artista sensible no se debe sustraer; lo mismo nos logran 
entusiasmar sus timbres desusados como descorazonar sus problemas mecánicos y desafinaciones. Sin embargo el mero hecho de hacer sonar una maquinaria compleja del pasado, con sus particularidades tímbricas, sus misterios y sorpresas acústicas, ofrece gratificaciones indescriptibles y altamente adictivas. La confección de un programa con obras idiomáticas para los órganos históricos mexicanos, interpretado de acuerdo a los criterios de la EHI y con la posibilidad de ejecutarse en un instrumento idóneo, es un desafiante reto apenas posible desde hace una treintena de años.

Hoy por hoy, la EHI resulta expresión del postmodernismo más radical, en su esfuerzo por revitalizar nuestra actual cultura musical, con un estilo único, distinto y original, que contribuye a la supervivencia y floración de la música occidental. No se trata de un regreso directo al pasado sino de una aventura artística, inspirada e informada por la historia, que nos lleva a desembocar en una nueva y total creación.

Después de todo el postmodernismo, huyendo del canon y el autoritarismo tradicionales, aún no ha sido capaz de precisar sus valores eclécticos y disímbolos, aceptando con entusiasmo lo que las vanguardias modernas hasta el fin del milenio condenaron.

A la fecha se ha rescatado y revitalizado una abrumadora cantidad de documentación, de partituras y de instrumentos que milagrosamente se salvaron de la incuria y el desdén de los siglos. Ahí está la historia y la musicología, para animar a los ejecutantes imaginativos a explorar y descubrir nuevos mundos sonoros, nuevas formas de expresión musical, sin olvidar que la búsqueda de la belleza, autenticidad y honestidad interpretativa, sólo se logra transmitir al oyente cuando nuestra interpretación representa un gozo compartido, basado en la profunda asimilación y maduración de un programa.

\section{BIBLIOGRAFÍA}

El presente ensayo histórico fue elaborado principalmente con materiales procedentes del Archivo del Cabildo Catedral Metropolitana de México (ACCMM). Otros materiales proceden del Archivo Histórico del Archivo General de Notarías (AHAGNN), del Archivo General de la Nación (AGN) y del Centro de Estudios de Historia de México (CEHM Carso), principalmente. Guillermo Tovar de Teresa, me facilitó generosamente su colección de transcripciones reunidas en dos carpetas con el título; Documentos inéditos para la historia del arte en México, Órganos SS. XVI-XVIII, transcripciones en copias mecanografiadas sin numeración de documentos procedentes de la Colección Cervantes, Archivo General de la Nación y del Archivo General de No- tarías, principalmente. Sus transcripciones modernizan la ortografía.

Butt, John: Playing with History; The historical Approach to Musical Performance, Cambridge, Cambridge University Press, 2002, $3^{\mathrm{a}}$. ed. Oxford University Press, 2005, trad. José Antonio Guzmán.

Castro Morales, Efraín, Los órganos de la Nueva España y sus artífices, Puebla, Gobierno del Estado, 1989.

Cea Galán, Andrés, "La eclosión de la simetría: el repertorio para los órganos de Julián de la Orden de Cuenca y Málaga, Estado de la cuestión”, El Libro de la 48 SMR, Cuenca, Gráficas Cuenca, 2009.

Correa de Arauxo, Francisco, Libro de Tientos y Discursos de Música Práctica y Theórica de órgano intitulado Facultad Orgánica. Alcalá de Henares, Antonio Arnao, 1626.

Crutchfield, Will, "Fashion, Conviction and Performance Style in an Age of Revivals". En Authenticity and Early Music a Symposium, Oxford, Oxford University Press, 1988, reimp. 1991, Introducción, trad. José Antonio Guzmán.

Cruz, Sor Juana Inés de la, Respuesta a Sor Filotea de la Cruz, México, Ed. Éxodo, 2005.

Dart, Thurston, The Interpretation of Music, Londres, Hutchinson's University Library, 1954, 4a . ed., 1967.

Davies, Stephen, "Authenticity in Musical Performance", British Journal of Aesthetics, 27 (1987), 39-50.

Dolmetsch, Arnold, The Interpretation of the Music of the XVII and XVIII Centuries, Londres, Novello, 1915 Reimpresión, con introducción de R. Alec Harman, Londres, 1969.

Donington, Robert: The Interpretation of Early Music, Londres, Faber \& Faber, 1979.

Dreyfus, Laurence: "Early Music Defended against its Devotees; a Theory of Historical Performance in the Twentieth Century", The Musical Quarterly, 69 (1983).

Estrada, Jesús, Música y músicos de la época virreinal, Reimp. México, Sep 70`s, Diana, SEP, 1980.

Flentrop, Dirk A., The Organs of Mexico Cathedral, Washington, Smithsonian Institution Press, 1986.

Guzmán Bravo, José Antonio, Los Órganos Gemelos de la Catedral Metropolitana de México. México, ENM, UNAM, 2013.

Guzmán Bravo, José Antonio y Stevenson, Robert, La Música de México: II.-Historia, Periodo Virreinal. México, UNAM, 1986. Revisada y en prensa, 2016.

Haynes, Bruce, The End of Early Music; A Period Performer's History of Music for the Twenty-First Century. Nueva York, Oxford University Press, 2007. Trad. José Antonio Guzmán. 
Hornbostel, Heinrich y Sachs, Kurt, "Systematik der Musikinstrumente", Zeitschrift für Ethnologie, 46 (Dent, 1914).

Hubbard, Frank, Three Centuries of Harpsichord Making, Cambridge Mass., Harvard University Press, 1965.

Kenyon, Nicholas, ed., Authenticity and Early Music a Symposium, Oxford University Press, R.U. 1988, reimp. 1991, Introducción. Trad. José Antonio Guzmán.

Landowska, Wanda, Landowska on Music. Nueva York, Ed. Denise Restout, 1964.

Lang, Paul Henry, Musicology and Performance. Boston, Yale University Press, 1997.

Mendel, Arthur: "Some Ambiguities of the Mensural System". en Studies in Music History: Essays for Oliver Strunk, ed. Harold Powers, Princeton University Press, Nueva Jersey, 1968.

Nassarre, Pablo, Escuela Música según la práctica moderna, I, II, Zaragoza 1723-1724, Ed. facsimilar, Zaragoza, Institución Fernando el Católico, 1980.

Pérez Villalta, Guillermo, Melancólico Rococó, Sevilla, Ed. Los Sentidos, 2010.

Quantz, Johann Joachim, Essai dúne méthode pour apprendre à jouer de la Flûte Traversière, Berlín, Chrétien Fréderic Voss, 1752.
Rainolter, Claudio, El Órgano de Longares, una restauración histórica, Zaragoza, Institución Fernando el Católico, 1985. Cita y traduce a Hope, Alfred, Das Wiederentdeckte Werkgemeimnis des Deutschen Orgelbaus.

San Vicente, Juan Manuel, Exacta Descripción de la Magnífica Corte Mexicana, Cabeza del Nuevo Americano Mundo, significada por sus essenciales partes, para el bastante conocimiento de su Grandeza, Cádiz, Imprenta de Francisco Rioja y Gamboa, 1768.

Toussaint, Manuel, La Catedral de México y el Sagrario Metropolitano, su historia, su tesoro, su arte, Ciudad de México, 1948, reimpresión, México, Editorial Porrúa, 1973.

Tovar de Teresa, Guillermo, Documentos para la Historia del arte en México, Órganos, siglos XVI-XVIII, transcripciones mecanografiadas sin numerar, integradas en dos álbumes.

- México Barroco, México, SAHOP, 1981.

- Los órganos de la catedral de México, México, ACHCM, 1983.

Vences, Magdalena, "El Coro", Catedral de México, patrimonio artístico y cultural, México, SEDUE, 2009. 